\title{
Progress on Ordered Intermetallic Electrocatalysts for Fuel Cells Application
}

\author{
Zhengrong Li, Tao Shen, Yezhou Hu, Ke Chen, Yun Lu, Deli Wang * \\ Key Laboratory of Material Chemistry for Energy Conversion and Storage (Huazhong University of Science and Technology), \\ School of Chemistry and Chemical Engineering, Huazhong University of Science and Technology, Wuhan 430074, China.
}

\begin{abstract}
Proton exchange membrane fuel cells (PEMFCs) are considered as one of the most promising energy conversion devices owing to their high power density, high energy conversion efficiency, environment-friendly merit, and low operating temperature. In the cathodic oxygen reduction reaction and anodic smallmolecule oxidation reactions, Pt shows excellent catalytic activity. However, several factors limit the practical application of Pt nanoparticles in fuel cells, such as the high price of $\mathrm{Pt}$, easy agglomeration during long-term cycling, and limited electrocatalytic performance. Alloying $\mathrm{Pt}$ with $3 d$-transition metal produces ligand and strain effects, which reduces the center of Pt- $d$ band and weakens the binding strength of oxygen species, thereby improving the catalytic activity and reducing the cost. However, the performance of fuel cells degrades seriously because the transition metals tend to dissolve in acidic electrolytes. The disordered alloy

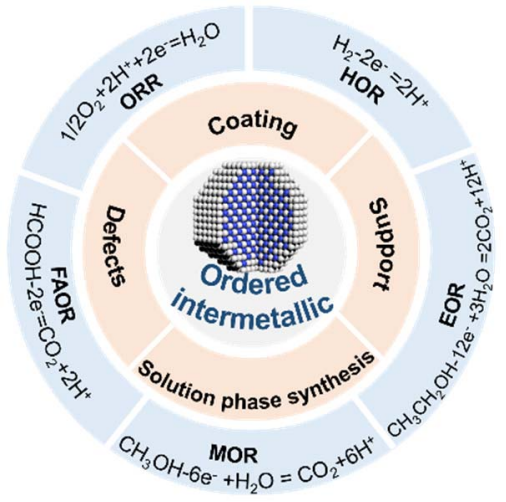
transformed into ordered intermetallic nanoparticles can prevent the dissolution of transition metals. Ordered intermetallics have highly ordered atomic arrangements and strong $\operatorname{Pt}(5 d)-\mathrm{M}(3 d)$ orbital interactions, which result in excellent stability in both acidic and alkaline electrolytes. Ordered intermetallic nanoparticles have attracted significant attention owing to their excellent electrocatalytic activity and stability, which can be attributed to controllable composition and structure. Pd has a similar electronic structure and lattice parameters to $\mathrm{Pt}$, and has thus attracted significant attention. Several Pd-based ordered intermetallics have been synthesized, and they exhibit sufficient catalytic performance. This review discusses the recent progress in noble metal-based ordered intermetallic electrocatalysts based on the research status of our group over the years. First, the structural characteristics and characterization methods of ordered intermetallic nanoparticles are introduced, exhibiting approaches to distinguish ordered and disordered phases. Then, the controllable preparation of ordered nanoparticles is highlighted, including thermal annealing and direct liquid phase synthesis. The migration and interdiffusion of atoms in the ordering process is very difficult. High-temperature thermal annealing is the most commonly used method for preparing intermetallics, which can precisely control the composition and atomic ordered arrangement. However, thermal annealing can only produce thermodynamically stable spherical nanoparticles. Supports and coating layers are usually employed to prevent agglomeration of nanoparticles at high temperatures. Finally, the applications of ordered intermetallic nanoparticles in fuel cell electrocatalysts are reviewed, including the oxygen reduction reaction (ORR), hydrogen oxidation reaction (HOR), formic acid oxidation reaction (FAOR), methanol oxidation reaction (MOR), and ethanol oxidation reaction (EOR). In addition, the current challenges and future development directions of the catalysts are discussed and discussed to provide new ideas for the development of fuel cell electrocatalysts.
\end{abstract}

Key Words: Fuel cell; Electrocatalysis; Intermetallics; Oxygen reduction reaction; Small-molecule oxidation

Received: October 14, 2020; Revised: December 1, 2020; Accepted: December 2, 2020; Published online: December 10, 2020.

*Corresponding author. Email: wangd181125@hust.edu.cn.

The project was supported by the National Natural Science Foundation of China (91963109).

国家自然科学基金(91963109)资助项目

(C) Editorial office of Acta Physico-Chimica Sinica 


\title{
有序金属间化合物电催化剂在燃料电池中的应用进展
}

\author{
李峥嵘, 申涛, 胡治州, 陈科, 陆望珼, 王得丽” \\ 华中科技大学化学与化工学院, 能量转换与存储材料化学教育部重点实验室, 武汉 430074
}

\begin{abstract}
摘要: 在燃料电池阴极氧还原反应以及阳极小分子氧化反应中, 结构有序的金属间化合物由于具有可控的组成和结构表 现出良好的电催化活性和催化稳定性，受到科研工作者的广泛关注。本文基于课题组多年来在有序金属间化合物电催化 剂方面的研究情况，综述了贵金属基有序金属间化合物电催化剂的研究现状。重点介绍了结构有序金属间化合物的结构 特点、表征方法、可控制备以及其在燃料电池电催化剂中的应用。此外，对这类材料当前存在的问题以及未来发展方向 进行了讨论及展望, 以期为燃料电池电催化剂的发展开拓新的思路。
\end{abstract}

关键词: 燃料电池; 电催化; 金属间化合物; 氧还原反应; 小分子氧化 中图分类号：0643

\section{1 引言}

随着全球经济的发展, 对于能源的需求量越 来越大, 加上不可再生能源的过度消耗, 人类面临 着资源圆竭和环境污染日益严重的问题。为了缓 解能源和环境危机, 开发和利用清洁能源迫在眉 睫 ${ }^{1}$ 。质子交换膜燃料电池(PEMFCs) 由于功率密度 高、能量转换效率高、环境友好、工作温度低等优 点, 被认为是最有前途的能量转换装置之一 2 。 PEMFCs的种类很多, 根据阳极通入的燃料种类可 以分为: 氢氧燃料电池 $(\mathrm{HOFC})$ 、直接甲酸燃料电 池(DFAFC)、直接甲醇燃料电池(DMFC)、直接乙 醇燃料电池(DEFC) 等。它可以直接将化学能转化 为电能, 具体运行机制是: 向阳极侧连续通入氢气 或有机小分子(甲醇、乙醇、甲酸等)发生氧化反应, 同时释放电子和质子, 阴极侧连续通入氧气发生 还原反应生成水。

为了使电化学转换反应的效率达到最大并使 能量损失降至最低, 需要使用合适的电催化剂 ${ }^{3}$, 理想的催化剂具有高活性、高选择性、优异的稳定 性以及低成本。在上述大多数反应中, 铂 $(\mathrm{Pt})$ 通常 是最高效的单金属电催化剂 ${ }^{4}$, 但目前存在很多因 素制约PEMFCs的实际应用。这些因素主要是: (1) 在阴极氧还原反应(ORR)中, $\mathrm{Pt}$ 与含氧中间体的结

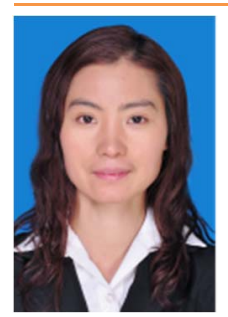

王得丽, 1981年生。2008年于武汉大学获 博士学位。2008-2012年先后在新加坡南 洋理工大学和美国康奈尔大学从事博士 后研究。2013年初入职华中科技大学化 学与化工学院任教授。获得中组部海外 高层次人才计划和教育部 “新世纪优秀 人才支持计划”。主要从事先进电化学能源材料方面的研 究工作。
合能较强, 使含氧中间体不易从催化剂表面解吸, 从而导致ORR动力学迟缓, 影响燃料电池整体性 能 5 。要使PEMFCs 达到较高的功率密度需要使用 高负载量的Pt催化剂。(2)较高载量的Pt在电催化 长时间循环过程中易发生团聚 6 , 使得电化学活性 面积减小影响催化活性和稳定性。(3) Pt储量稀缺, 价格较昂贵, 目前 $\mathrm{Pt}$ 基催化剂及相关催化剂层的 成本占据PEMFCs 中组件总成本的 $55 \%$ 以上 ${ }^{7}$, 使得 PEMFCs的发展受到成本制约。(4)在甲酸氧化反 应(FAOR)、甲醇氧化反应(MOR)、乙醇氧化反应 (EOR)等小分子氧化反应中, 中间产物 $\mathrm{CO}$ 吸附在 $\mathrm{Pt}$ 表面, 占据活性位点, 导致催化剂中毒 ${ }^{8}$ 。以上 因素严重阻碍了PEMFCs的商业化应用。如何降低 催化剂成本、提升催化剂的活性与稳定性是目前 的研究热点。研究发现, $\mathrm{Pt}$ 与 $3 d$ 过渡金属 $\mathrm{M}(\mathrm{M}=$ $\mathrm{Cu}^{9-11}, \mathrm{Fe}^{12-14}, \mathrm{Ni}^{15,16}, \mathrm{Co}{ }^{17}$ 等)形成PtM合金, 会发生 $\mathrm{Pt}(5 d)-\mathrm{M}(3 d)$ 轨道耦合, 改变 $\mathrm{Pt} 5 d$ 带空位、 $\mathrm{Pt}-\mathrm{Pt}$ 原子间距和Pt配位数, 使得Pt- $d$ 带中心下移, 远离费米能级, 从而改变Pt的电子结构, 削弱Pt表 面原子与含氧物种的结合能, 提升催化剂的活性 与稳定性 ${ }^{18,19}$ 。这可以归因于两种金属结合产生了 多种效应(图1) ${ }^{3}$ 。

(1)配体效应(ligand effect): 配体效应是指催 化剂表面的吸附位点附近两个不同原子之间发生 电荷转移, 导致材料的吸附性能发生改变 ${ }^{20}$ 。向 $\mathrm{Pt}$ 中引入第二种金属 $\mathrm{M}$, 两个不同表面原子之间, 部 分电子会向具有高电负性的元素转移, 从而改变 金属表面的电子结构和活性, 使 $\mathrm{Pt}$ 的 $d$ 带中心偏离 费米能级(图1a) ${ }^{21}$; 另外, 在PtM@Pt核壳结构催化 剂中, 当 $\mathrm{Pt}$ 壳小于 $0.6 \mathrm{~nm}$, 核/壳原子之间发生电荷 转移也会产生配体效应 ${ }^{20}$ 。 

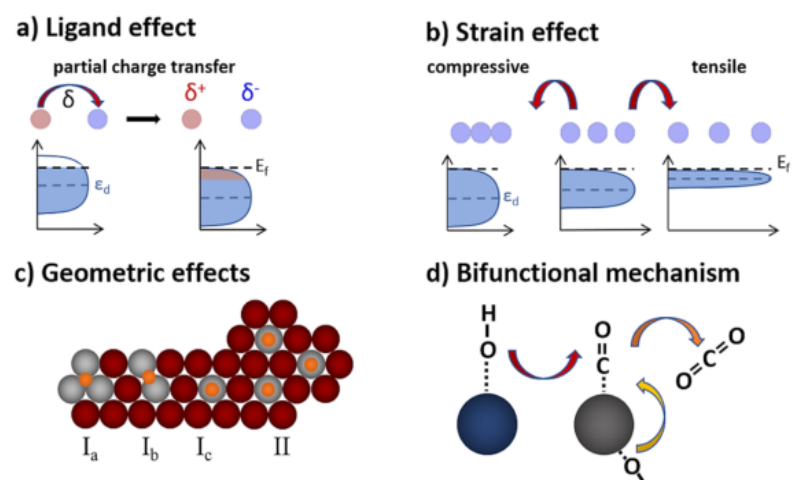

d) Bifunctional mechanism

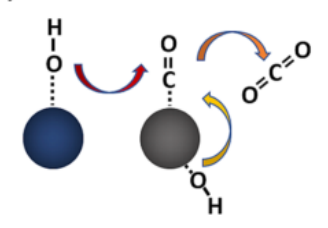

图1 合金中的多种效应 ${ }^{3}$

Fig. 1 Various optimization effects in alloys ${ }^{3}$.

Adapted from American Chemical Society Publisher.

(2)应变效应(strain effect): 具有核壳结构的催 化剂, PtM合金内核与贵金属外壳之间存在相互作 用, 壳层原子会适应底层晶体结构, 原子之间的距 离会变得更长或更短, 从而产生压缩或拉伸应变, 使 $d$ 带中心移动(图 $1 \mathrm{~b})^{22}$; 因为合金的应变效应和 配体效应都会引起原子轨道重叠和 $d$ 带中心的变 化，因此这两种效应很难区分，往往相互关联。

(3)几何效应(geometric effects): 在Pt的表面晶 格中嵌入第二种元素 $\mathrm{M}$ 形成合金或金属间化合物 相, 会改变催化剂表面的几何环境(图1c)。M可以 把Pt隔离开, 孤立的Pt原子只能吸附顶部的原子或 分子(图1 c- $\mathrm{I}_{\mathrm{a}}$ ), 两个 $\mathrm{Pt}$ 原子可以导致桥联吸附(图 $1 \mathrm{c}-\mathrm{I}_{\mathrm{b}}$ ), 即在原子之间; 而三个原子的集合允许反 应物分子在中空位进行反应(图1 $\mathrm{c}-\mathrm{I}_{\mathrm{c}}$ ), 可有效提升 反应的选择性 ${ }^{23}$ 。

(4)双功能机理(bifunctional mechanism): 如果引 入的金属比Pt更亲氧, 容易促进电解液中水解离产 生 $\mathrm{OH}^{*}$, 促使 $\mathrm{Pt}$ 上的含氧中间体 (多为 $\mathrm{CO}$ ) 在低电位 下反应，抑制其毒化反应活性位点(图1d) ${ }^{24-26}$ 。

由于扩散势垒的存在, 制备的Pt基合金通常 是无序固溶体, 其中Pt和M随机占据面心立方位。 研究表明, 这些无序PtM合金催化剂在酸性电解液 的循环过程中, 表面的 M原子会迅速溶解到电解 质中, 留下低配位的Pt表面, 使稳定性降低 ${ }^{27}$ 。另 外 $\mathrm{M}$ 与 $\mathrm{Pt}$ 之间的配体效应和应变效应也会改变, 从 而导致燃料电池在实际运行过程中性能严重衰 减。如何抑制非贵金属溶出, 提升催化剂的稳定性 至关重要。研究发现, 催化剂的活性和稳定性不仅 与其组成有关, 而且与其结构高度相关 ${ }^{28}$ 。王得丽 课题组 ${ }^{17,29-31}$ 发展了将无序固溶体合金转变为有 序金属间化合物的策略, 使材料的活性与稳定性 得到了极大的提升。与无序固溶体合金相比, 有序
金属间化合物中原子有序排列，表现出更高的混 合焓和更强的 $\operatorname{Pt}(5 d)-\mathrm{M}(3 d)$ 轨道相互作用, 可以阻 止过渡金属 $\mathrm{M}$ 的溶解, 在酸性和碱性电解液中都 具有优异的结构稳定性 ${ }^{32-34}$, 使其成为非常有前景 的燃料电池催化剂。王得丽等 ${ }^{17}$ 早在 2012 年发现了 结构有序化对 ORR性能的影响, 将无序 $\mathrm{Pt}_{3} \mathrm{Co}$ 纳米 晶在还原性 $\mathrm{H}_{2}$ 气氛中 $700{ }^{\circ} \mathrm{C}$ 高温退火得到了有序 $\mathrm{Pt}_{3} \mathrm{Co}$, 相对于无序结构, 质量活性(MA)与比活性 (SA)均有了大幅提升, 且具有极优异的循环稳定 性。Sun等 ${ }^{35}$ 将无序面心立方 $\mathrm{fcc}-\mathrm{PtFe}$ 在 $\mathrm{Ar} / \mathrm{H}_{2}$ 混合 气中 $750^{\circ} \mathrm{C}$ 热退火得到了有序面心四方 fct-PtFe, 催 化剂的活性与稳定性有了大幅提升。Hodnik等 ${ }^{10}$ 发 现有序的 $\mathrm{Pt}_{3} \mathrm{Cu}$ 纳米晶的ORR活性与稳定性远优 于无序 $\mathrm{Pt}_{3} \mathrm{Cu}_{\circ}$ Z Zou等 ${ }^{36}$ 比较了无序和有序的 $\mathrm{Pt}_{3} \mathrm{Cr}$ 催 化剂的ORR活性和耐久性, 5000周加速稳定性测 试后, 有序 $\mathrm{Pt}_{3} \mathrm{Cr}$ 金属间化合物纳米晶的ORR的MA 几乎没有衰减。Gan等 ${ }^{37}$ 通过扫描透射电子显微镜 (STEM) 和光谱分析, 发现有序PtCo 与无序 PtCo 相 比, 循环过程中Co和Pt的溶解都得到了极大的缓解。

近些年, $\mathrm{Pd}$ 基金属间化合物催化剂也引起了 人们的关注。在元素周期表中, Pt、Pd同族, 具有 相似的电子结构和晶格常数, Pd的ORR活性也接 近于 $\mathrm{Pt}$, 同时 Pd比Pt储量丰富, 是Pt催化剂良好的 替代品 $8,38-40$ 。王得丽课题组 ${ }^{41}$ 制备了富 $\mathrm{Pt}$ 壳的有序 $\mathrm{PdFe}$ 金属间化合物催化剂, 将其作为锌空电池的 正极材料, 比无序PdFe@Pt 具有更高的电压和峰值 功率密度。与无序相相比, 有序 $\mathrm{PdBi}$ 金属间化合物 抗 $\mathrm{CO}$ 毒化能力更强, 对甲酸氧化反应(FAOR)表现 出更高的活性和耐久性 ${ }^{42}$ 。Yin等 ${ }^{43}$ 制备了有序 $\mathrm{Pd}_{3} \mathrm{Fe}$ 纳米晶, 作为 $\mathrm{ORR}$ 催化剂, 在 $0.8 \mathrm{~V}$ (vs. RHE) 时的 $\mathrm{SA}$ 是无序 $\mathrm{Pd}_{3} \mathrm{Fe}$ 的 2.4 倍, 且 1000 周循环后, 电 化学活性面积几乎没有衰减。具有优异活性与稳 定性的金属间化合物纳米晶引起了科研工作者的 广泛研究 ${ }^{44-47}$ 。

\section{2 金属间化合物的结构特点与表征方法}

\section{1 结构特点}

有序金属间化合物具有固定化学计量比和高 度有序的原子结构, 每个原子都有其固定占位。作 为一种具有特殊结构的合金, 其中金属原子通过 强 $d$ 轨道作用相互结合, 并按特定的晶体学方向有 序排列(图2) ${ }^{48}$ 。

无序合金一般是金属(或含少许非金属)混合 排布组成的固溶体, 其中原子随机分布在晶格上; 而有序金属间化合物，每个组成元素的原子都有 特定的位置, 从而可以实现对结构和电子效应的 


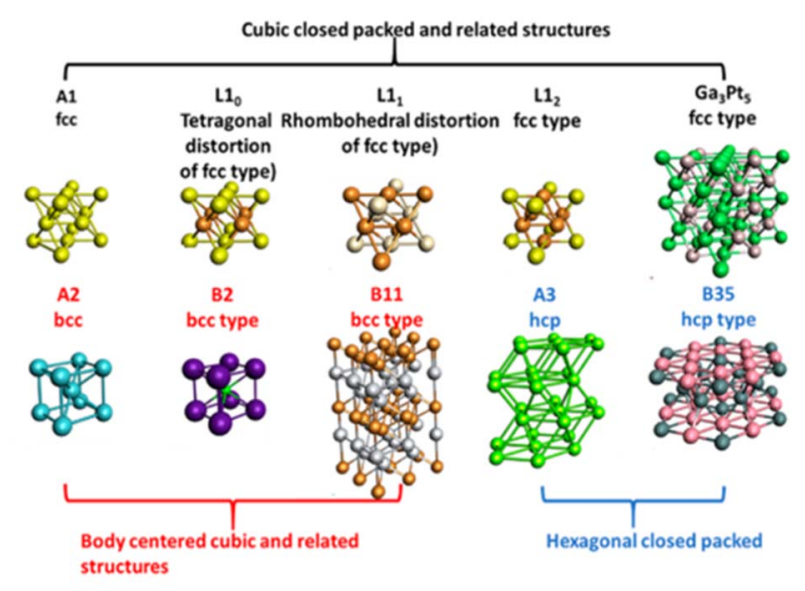

图2 常见合金及相应的金属间化合物结构 48

Fig. 2 Schematic diagram of common alloy and intermetallic structures ${ }^{48}$.

Adapted from American Chemical Society Publisher.

可预测调控 ${ }^{49-52}$ 。与固溶体合金相比, 金属间化合 物由于较低的生成焓以及较强的原子间相互作用, 使得其抗氧化以及抗腐蚀性能得到明显改善 53,54 。 从图 2 中可以看出, 面心立方相(fcc)固溶体为 $\mathrm{A} 1$ 结 构, 不改变晶体结构将其中部分原子取代, 可得到 $\mathrm{L} 1_{0} 、 \mathrm{~L}_{1} 、 \mathrm{~L}_{2} 、 \mathrm{Ga}_{3} \mathrm{Pt}_{5}$ 相的有序金属间化合物。体 心立方相(bcc)固溶体为A2结构, 其对应的金属间 化合物为 B2 和 B11相。密排六方相 (hcp) 固溶体为 $\mathrm{A} 3$ 结构, 其对应的金属间化合物为 B35相 48 。即使 无序合金和有序金属间化合物纳米晶的组成和化 学计量比完全相同, 但由于晶体结构和表面结构 的不同, 导致不同的含氧物种结合能, 进而影响材 料的催化活性和结构稳定性。

\section{2 表征方法}

有序金属间化合物结构可以通过衍射图案(例 如选区电子衍射(SAED)或X射线衍射(XRD)) 来识 别, 也可以通过高分辨率透射电子显微镜 (HRTEM) 图像来判断。图3a所示的XRD图谱中可 以看到, fct-PtFe相比于 fcc-PtFe, 出现了额外的 (001)、(110)、(002)、(201)、(112)、(202)、(221)和 (310)等超晶格衍射峰, 表明了原子的有序排列。 图 3b 中 SAED 衍射图中的亮斑对应于 fct-PtFe 的 (001)、(111)、(200)、(220)和(202)面，再次证实了 fct-PtFe相的形成。图3c-e中可以看到两个不同的 晶格间距, 其中 $0.192 \mathrm{~nm}$ 对应于 fct-FePt的(110)晶 面(0.193 nm, JCPDS No. 65-1051), 同样也能证明 生成了fct-PtFe有序金属间化合物。由于不同元素 的原子强度与平均原子数的平方成正比, 使得 $\mathrm{Pt}$ 原 子比 $\mathrm{Fe}$ 原子表现出更高的强度和亮度。在图3 $\mathrm{e}$ 环 形暗场图像中可以直接观察到原子的有序排列 ${ }^{55}$ 。

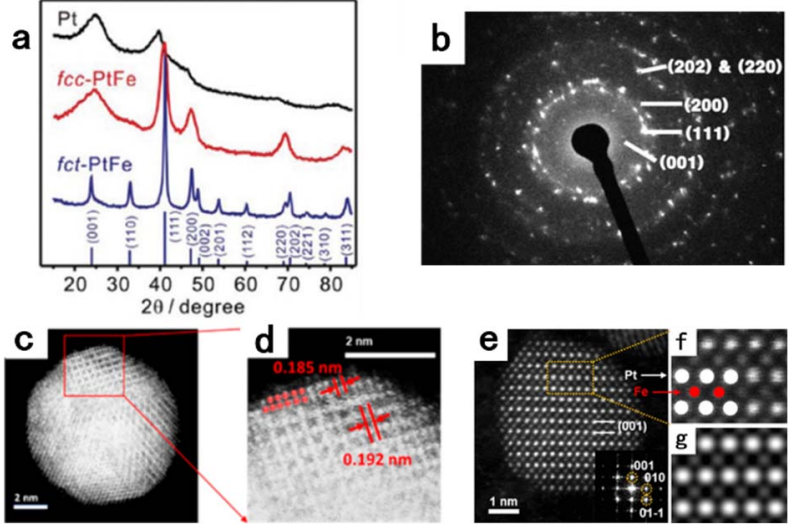

图3 (a) Pt、fcc-PtFe、fct-PtFe的XRD衍射图 ${ }^{47}$;

(b) fct-PtFe的SAED衍射图 ${ }^{56}$; (c、d、e) fct-PtFe的

HAADF-STEM图像 ${ }^{57}$; (f) fct-PtFe的放大图像,

(g) fct-PtFe的模拟图像 ${ }^{55}$

Fig. 3 (a) XRD patterns for Pt, fcc-PtFe and fct-PtFe ${ }^{47}$;

(b) SAED patterns for fct-PtFe ${ }^{56}$; (c, d, e) the HRTEM

images of fct-PtFe ${ }^{57}$; enlarged image (f) and simulated image (g) of fct-PtFe ${ }^{55}$.

(a) Adapted from Royal Society of Chemistry Publisher. (b) Adapted from Wiley Publisher. (c-g) Adapted from American Chemical Society Publisher.

\section{3 制备方法}

有序金属间化合物由于具有规则的原子排列 和强 $d-d$ 轨道相互作用, 展现出优异的催化性能。 通常需要在高温条件下制备, 高温可以促进金属 原子的有序排列和 $d-d$ 轨道杂化 ${ }^{48}$ 。合成方法可分 为两种：热退火法和直接液相合成法(表 1$)$ 。热退 火法一般是先采用液相法制备得到无序合金纳米 晶, 然后在情性气氛中经过合适的温度退火处理 引发金属原子在晶格内的相互扩散，以形成有序 结构。热退火是将无序合金转变成有序金属间化 合物最常用的方法, 但一般需要控制退火温度、退 火时间以及选择合适的载体和包覆层以防止纳米 晶在高温下的团聚 $12,57,58$ 。直接液相合成法是在液 相中直接合成有序金属间化合物 ${ }^{59-61}$, 这种方法可 以在较低的温度下得到有序结构。但因为金属前 驱体的还原电位相差较大, 一般需要强还原剂来 促使两种金属前驱体同时还原出来。

\section{1 热退火法}

金属间化合物的形成通常需要高温退火。高温 退火可以降低原子扩散势垒, 增大原子迁移率, 促 使其有序排列。为了获得完全有序的原子排列, 退 火温度通常高于 $500{ }^{\circ} \mathrm{C}$ 。但由于纳米晶颗粒较小, 具有高比表面自由能, 较高的退火温度会促使奥 斯特瓦尔德熟化 (Ostwald ripening) 和聚结, 导致纳 米晶粒径增大和尺寸分布不均，降低金属间化合 
物纳米晶的催化性能。为抑制纳米晶的尺寸增长, 可以通过将纳米晶分散在稳定的载体上, 包覆聚 合物、氧化物 $\left(\mathrm{SiO}_{2} 、 \mathrm{MgO} 、 \mathrm{Al}_{2} \mathrm{O}_{3}\right.$ 等) 保护层, 以及 加入 $\mathrm{KCl}$ 基质等来解决。

\section{1 .1 载体}

将纳米晶分散在具有较大表面积的稳定载体 上(例如多孔碳、多孔金属氧化物/碳复合物、石墨 烯等), 可以对纳米晶产生强大的针定作用, 减缓 其在高温下的迁移, 从而抑制团聚。另外, 由于在 金属纳米晶和载体之间的界面上两者会发生电子 重排 ${ }^{62}$, 可以提高纳米晶的电子密度, 从而达到催 化性能的提升 ${ }^{53}$ 。导电载体(石墨等)和半导电载体 (可还原金属氧化物等)可与金属之间发生电荷转 移, 也可以通过掺杂对载体进行改性以增强导电 性 ${ }^{63}$ 。王得丽课题组 ${ }^{17}$ 以Vulcan XC-72为载体, 采 用浸渍还原法在 $150{ }^{\circ} \mathrm{C} 、 5 \% \mathrm{H}_{2} / 95 \% \mathrm{~N}_{2}$ 混合气中 热退火气相还原 $2 \mathrm{~h}$ 制备了无序 $\mathrm{Pt}_{3} \mathrm{Co} / \mathrm{C}$ 纳米晶, 随 后 $700{ }^{\circ} \mathrm{C}$ 热退火促使原子有序化排列制备得到了 $\mathrm{L} 1_{2}$ 有序 $\mathrm{Pt}_{3} \mathrm{Co} / \mathrm{C}$ 纳米晶, XRD图谱中出现(100)和 (110)超晶格衍射峰表明了有序相的生成。所得有
序 $\mathrm{Pt}_{3} \mathrm{Co} / \mathrm{C}$ 纳米晶的粒径仅有 $7.2 \pm 1 \mathrm{~nm}$, 相对于 $\mathrm{Pt} / \mathrm{C}$ 粒径增长不到 $3 \mathrm{~nm}$ 。载体不仅可以控制材料的 粒径, 提升分散性, 而且可以提高材料的导电性。 将多孔碳与氧化物复合作为载体同样可用于合成 分散良好的金属间化合物。Lee等 ${ }^{64,65}$ 以有序大孔 介孔碳/二氧化硅(OMCS)和介孔碳/硅酸铝作为载 体，通过后续热退火分别合成了有序 $\mathrm{PtPb}$ 和有序 $\mathrm{FePt}$ 纳米晶, 纳米晶被包裹在有序的孔洞中, 限制 了粒径的增长(图4a)。另外他们还发现, 金属负载 量过高会导致纳米晶的团聚。

通过在有序介孔碳中加入具有强电负性的元 素进行改性可以增强对金属前驱体的吸附作用以 抑制纳米晶的增长。 $\mathrm{J}$ 等 ${ }^{51}$ 以 $\mathrm{S}$ 元素修饰有序介孔 碳(OMC)表面, 得到了表面改性的OMC-S作为催 化剂载体, 制备了嵌在有序介孔碳(OMC)多孔结 构中的 OMC-PtBi纳米晶(图4b)。因为 $\mathrm{OMC}$ 具有相 互连通的孔结构、窄的孔径分布和高比表面积, 并 且 $S$ 元素对金属有很强的亲和力, 可以将溶液中的 金属前驱体吸附并结合到 $\mathrm{OMC}$ 的孔洞中, 并在还 原过程中限制颗粒生长，从而得到超细分散的金
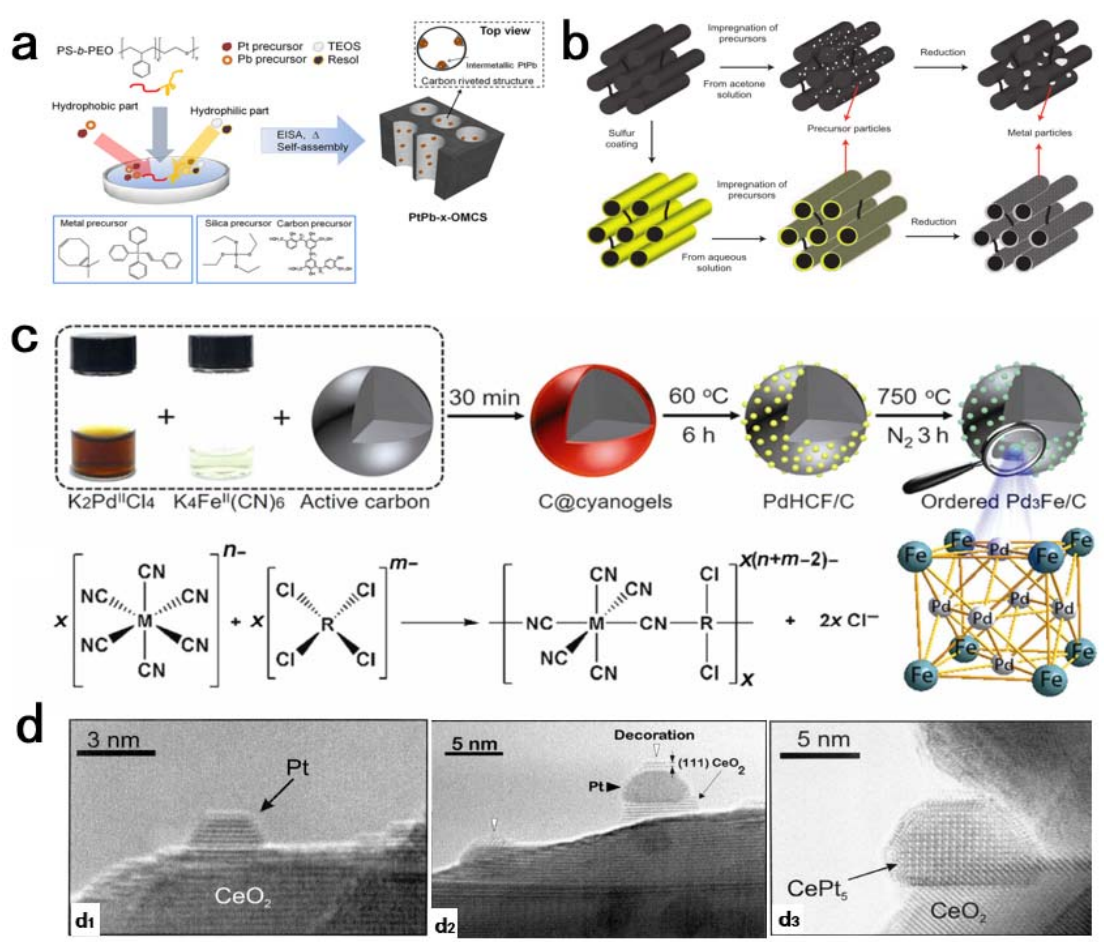

图4 (a) PtPb- $x$-OMCS催化剂的合成示意图 ${ }^{64}$; (b) OMC-PtBi催化剂的合成示意图 ${ }^{51}$; (c) 有序 $\mathrm{Pd}_{3} \mathrm{Fe} / \mathrm{C}$ 催化剂的 合成示意图 ${ }^{66} ;(d) \mathrm{CeO}_{2}$ 负载的 $\mathrm{Pt}$ 纳米晶 $\left(\mathrm{d}_{1}\right) 、 \mathrm{CeO}_{2}$ 修饰的 $\mathrm{Pt}$ 纳米晶 $\left(\mathrm{d}_{2}\right)$ 和 $500{ }^{\circ} \mathrm{C}^{\circ} \mathrm{H}_{2}$ 气氛中退火后的 CePt5 金属间化合物 $\left(\mathrm{d}_{3}\right)$ 的HRTEM图像 ${ }^{76}$

Fig. 4 (a) Synthesis schematic of PtPb-x-OMCS catalysts ${ }^{64}$; (b) synthesis schematic of OMC-PtBi catalysts ${ }^{51}$; (c) synthesis schematic of ordered $\mathrm{Pd}_{3} \mathrm{Fe} / \mathrm{C}$ catalysts ${ }^{66}$; (d) the HRTEM images of Pt nanoparticles supported on $\mathrm{CeO}_{2}\left(\mathrm{~d}_{1}\right)$, decoration of the Pt nanoparticles by $\mathrm{CeO}_{2}\left(\mathrm{~d}_{2}\right)$, the $\mathrm{CePt}$ intermetallic nanoparticles after annealing in $\mathrm{H}_{2}$ at $500{ }^{\circ} \mathrm{C}\left(\mathrm{d}_{3}\right)^{76}$.

(a) Adapted from American Chemical Society Publisher. (b, c) Adapted from Springer Nature publisher. (d) Adapted from Elsevier Publisher. 
属纳米晶。透射电子显微镜(TEM)图像显示所得纳 米晶粒径大概为 $2-3 \mathrm{~nm}$, 且尺寸分布均匀。 Tang 等 ${ }^{66}$ 采用碳载氧凝胶 $\left(\mathrm{K}_{2} \mathrm{Pd}^{\mathrm{II}} \mathrm{Cl}_{4} / \mathrm{K}_{4} \mathrm{Fe}^{\mathrm{II}}(\mathrm{CN})_{6}\right)$ 作为 前驱体，合成了有序 $\mathrm{Pd}_{3} \mathrm{Fe} / \mathrm{C}$ 金属间化合物(图4c), 氧凝胶配体中的 $\mathrm{N}$ 元素可以有效抑制 $\mathrm{Pd}^{0}$ 和 $\mathrm{Fe}^{0}$ 晶 核在晶体中的运动。石墨烯和碳纳米管由于具有 大的比表面积、优异的导电性和低的热膨胀系数, 也被用于分散纳米晶, 抑制其高温退火过程中的 团聚。 $\mathrm{Li}$ 等 ${ }^{67}$ 以碳纳米管为载体, 利用 $\mathrm{NaBH}$ 化学 还原法和后退火制备了 $\mathrm{L} 1_{0}$ 有序 $\mathrm{PtFe} @ \mathrm{Pt}$ 纳米晶, 其 分散性良好, 电化学活性面积高达 $80 \mathrm{~m}^{2} \cdot \mathrm{g}^{-1}$, 将其 用于ORR, 具有极高的催化活性和优异的耐久性。 另外, 以石墨烯为载体, 已有报道成功制备 $\mathrm{GaPt}_{3}$ 、 $\mathrm{GaPt}_{2}{ }^{68}$ 和 $\mathrm{PdAu}$ 等纳米晶 ${ }^{69}$ 。

ZIF 热解衍生的纳米碳材料具有高比表面积、 多孔结构以及三维骨架, 将金属纳米晶负载在 ZIF 分子篮上, 通过一步热解可以得到具有高活性、高 稳定性的Pt/PdM金属间化合物。在ZIF分子篮的孔 道里原位生长纳米晶, 可以限制纳米晶的增长, 同 时提高与碳载体的接触面积, 有效提升催化剂的

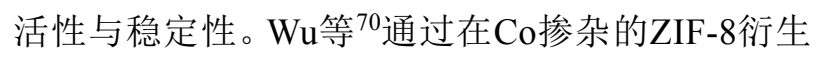
碳上对 Pt纳米晶进行 $900{ }^{\circ} \mathrm{C}$ 热处理, 分散的 Co 原子 首先嵌入到ZIF-8衍生碳, 然后扩散到Pt纳米晶中, 形成有序的 $\mathrm{Pt}_{3} \mathrm{Co}$ 。Peng等 ${ }^{71}$ 通过热解 $\mathrm{PtFe}$ 共掺杂 的ZIF-8得到了 $\mathrm{N}$ 掺杂介孔碳负载的 $\mathrm{Fe}_{3} \mathrm{Pt}$ 金属间化 合物纳米晶(图5a), 从 TEM图像中看到了元素的均 匀分布(图 $5 b$ ), 其具有高比表面积以及高 $\mathrm{N}$ 掺杂 量, 具有优异的ORR活性。Huang等 72 通过热解包 裹贵金属纳米晶的ZIF-8制备了 PtZn金属间化合物 纳米晶, 粒径为 $4 \mathrm{~nm}$ 左右。 ZIF-8不仅可以作为掺 $\mathrm{N} 、 \mathrm{C}$ 的前驱体, 还可以作为 Zn源与被包裹的金属 形成金属间化合物或合金纳米晶。后续作者发现, a

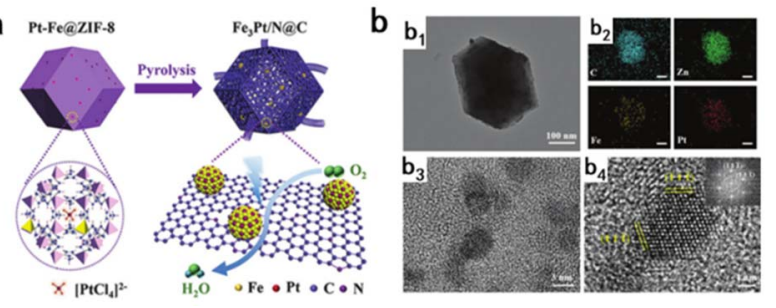

图5 (a) Fe3Pt/N@C催化剂的合成示意图; $\left(b_{3} 、 b_{4}\right)$ 和各元素mapping图(b2) ${ }^{71}$

Fig. 5 (a) Synthesis schematic of $\mathrm{Fe}_{3} \mathrm{Pt} / \mathrm{N} @ \mathrm{C}$ catalysts;

(b) TEM image ( $\left.b_{1}\right)$, HRTEM images $\left(b_{3}, b_{4}\right)$ and elemental mapping images ( $\left.b_{2}\right)$ of Pt-Fe@ZIF-8 ${ }^{71}$.

Adapted from Royal Society of Chemistry Publisher.
通过改变金属前驱体的种类，还可以制备不同种 类的贵金属纳米晶(PdZn、RhZn等)。这种方法为 合成具有小粒径、高分散的金属间化合物提供了 良好的策略 ${ }^{73,74}$ 。

另外，通过金属-载体的强相互作用可以在金 属和载体的界面制备有序金属间化合物。一般是 由氧化物载体担载贵金属纳米晶, 高温还原转化 为金属间化合物 ${ }^{75}$ 。Bernal等 ${ }^{76}$ 在 $\mathrm{H}_{2}$ 气氛中, 200 $950^{\circ} \mathrm{C}$ 高温还原 $\mathrm{Pt} / \mathrm{CeO}_{2}$, 用HRTEM观察其结构转 化, 发现负载在 $\mathrm{CeO}_{2}$ 上的 $\mathrm{Pt}$ 纳米晶在高温退火后 可以转化为金属间化合物 $\mathrm{CePt}_{5}$ (图4d)。但是能与 金属在界面发生强相互作用的氧化物载体一般导 电性很差, 且需要较高温度长时间热退火才能转 化为有序结构，故将该方法应用于金属间化合物 纳米晶的合成仍然具有挑战性。

\section{1 .2 包覆}

在纳米晶表面包覆聚合物、氧化物 $\left(\mathrm{SiO}_{2}\right.$ 、 $\mathrm{MgO} 、 \mathrm{Al}_{2} \mathrm{O}_{3}$ ) 保护层和 $\mathrm{KCl}$ 基质等, 可以消除纳米 晶之间的扩散, 从而有效缓解热退火过程中的团 聚和烧结, 精确控制纳米晶的尺寸 77 。但是包覆层 也大大限制了原子在热退火过程中的迁移，增大 了有序化过程中的势垒, 导致从无序相到有序相 之间的转变更加困难, 所以一般需要更高的退火 温度。

将 $\mathrm{N}$ 掺杂碳作为包覆层, 碳包覆主要起到了限 域作用而 $\mathrm{N}$ 元素起针定作用, 可以抑制颗粒长大, 提高催化活性和稳定性。多巴胺富含 $\mathrm{N}$ 元素和 C元 素, 在纳米晶表面原位聚合多巴胺, 后续热退火可 以在原位碳包覆的同时实现 $\mathrm{N}$ 掺杂。Chung等 ${ }^{14}$ 将 负载在碳颗粒上的无序 $\mathrm{fcc}-\mathrm{PtFe}$ 纳米晶浸渍盐酸 多巴胺溶液, 后 $700{ }^{\circ} \mathrm{C}$ 热退火得到多巴胺原位热解 形成的 $\mathrm{N}$ 掺杂碳壳包覆的有序 fct-PtFe纳米晶(图 $6 a)$, 高角度环形暗场扫描透射电子显微镜 (HAADF-STEM) 和快速傅立叶变换(FFT)分析证 实了有序相的形成。所得 $\mathrm{N}$ 掺杂碳包覆的有序 fct$\mathrm{PtFe}$ 纳米晶粒径仅 $6.5 \mathrm{~nm}$, 而未经包覆的 $\mathrm{PtFe}$ 纳米 晶粒径达 $10 \mathrm{~nm}$, 说明原位形成的掺 $\mathrm{N}$ 碳壳可以有 效抑制热退火过程中纳米晶的团聚。另外, 由于碳 壳具有较大的孔隙, 可以促进反应物分子渗透, 故 在保护纳米晶的同时, 又可以有效提升催化性能。

王得丽课题组 ${ }^{78}$ 采用一步高温热解法, 在浸渍 过程中先将双氧胺、 $\mathrm{Pt}$ 前驱体、 $\mathrm{Fe}$ 前驱体以及碳载 体实现均匀混合, 并通过后续 $800^{\circ} \mathrm{C}$ 高温热处理得 到了具有超薄 $\mathrm{N}$ 掺杂碳层包覆的有序 $\mathrm{Pt}-\mathrm{Fe}$ 金属间 化合物(图6b), 由图 $6 b_{1}$ 中可以看到所得纳米晶的 平均粒径仅 $3.8 \mathrm{~nm}$ 。其中双氧胺在 $550^{\circ} \mathrm{C}$ 时生成石 
墨氮化碳 $\left(\mathrm{g}-\mathrm{C}_{3} \mathrm{~N}_{4}\right)$, 随着温度升高到 $800{ }^{\circ} \mathrm{C}$ 时 $\mathrm{g}$ $\mathrm{C}_{3} \mathrm{~N}_{4}$ 分解, 从而实现 $\mathrm{N}$ 掺杂碳层的原位包覆。后续 通过这种方法同样成功制备出 $\mathrm{N}$ 掺杂碳层包覆的 有序Pd-Fe金属间化合物 ${ }^{38}$, 表明该方法具有一定 程度的普适性, 并且相对简单的制备过程也为后 续催化剂规模化生产提供了可能。

Fujimori等 ${ }^{79}$ 在无序 fcc-FePt表面包覆 $\mathrm{SiO}_{2}$, 随 后热退火得到有序 $\mathrm{L}_{0}-\mathrm{FePt}$ 纳米晶, $\mathrm{SiO}_{2}$ 纳米反应 器可以限制退火过程中 $\mathrm{Fe}$ 原子和 $\mathrm{Pt}$ 原子的扩散, 所 得材料平均粒径为 $6.4 \mathrm{~nm}$ 。Huang 等 ${ }^{80}$ 通过牺牲 $\mathrm{SiO}_{2}$ 壳制备了多壁碳纳米管(MWNT) 负载的 PtZn 金属间化合物纳米晶 (图 6c), 介孔二氧化硅 $\left(\mathrm{mSiO}_{2}\right)$ 壳层可以有效防止纳米晶在高温退火中 的团聚, PtZn纳米晶粒径为 $2.1 \pm 0.3 \mathrm{~nm}$, 并且均 匀分散在MWNT上。采用相同方法不加 $\mathrm{SiO}_{2}$ 壳制 备了 $\mathrm{PtZn} / \mathrm{MWNT}$, 粒径为 $27 \pm 20 \mathrm{~nm}$, 比加入 $\mathrm{SiO}_{2}$ 限域制备的PtZn纳米晶的粒径大近13倍, 证明了 $\mathrm{SiO}_{2}$ 包覆的有效性。王得丽课题组 ${ }^{81}$ 通过浸渍还原 法制备了有序 $\mathrm{Pd}_{2} \mathrm{FeCo}$ 催化剂, 热退火过程中在纳 米晶表面原位形成了 $\mathrm{Fe}_{2} \mathrm{O}_{3}$ 壳层, 有效抑制了纳米
晶团聚和奥斯特瓦尔德熟化, 所得 $\mathrm{Pd}_{2} \mathrm{FeCo}$ 纳米晶 的尺寸仅 $6.5 \mathrm{~nm}$ 。类似地, Kim等 82 在油胺-十八烯 体系中制备得到无序 $\mathrm{fcc}-\mathrm{FePt}$ 纳米晶, 随后在纳米 晶上包覆 $\mathrm{MgO}$ 作为保护层, 后续 $800{ }^{\circ} \mathrm{C}$ 对 fcc$\mathrm{FePt} / \mathrm{MgO}$ 纳米晶进行热处理得到了有序 $\mathrm{fct}-\mathrm{FePt}$ 。 核壳结构 $\mathrm{FePt} / \mathrm{MgO}$ 中的 $\mathrm{MgO}$ 壳层可以保护 $\mathrm{FePt}$, 抑 制其在高温下烧结, 但通过HRTEM图像发现, fcc$\mathrm{FePt}$ 纳米粒子嵌入到 $\mathrm{MgO}$ 中后, 由于 $\mathrm{Fe} 、 \mathrm{Pt}$ 的原子 迁移在退火过程中受到限制, 很难实现向 fct-FePt 的完全结构转变, 所得产物为部分有序结构。

不溶性副产物 $\mathrm{KCl}$ 基质作为包覆剂也可以有 效阻止有序化过程中纳米晶的团聚/烧结。Chen 等 83 发明了一种无表面活性剂的纳米晶 $-\mathrm{KCl}$ 基质 方法, 用于合成结构和尺寸可控的有序 $\mathrm{Pt}_{3} \mathrm{Fe}$ 纳米 晶。这种方法是在室温下四氢呋喃溶液中一锅还 原得到无序 $\mathrm{Pt}_{3} \mathrm{Fe}$ 纳米晶 $-\mathrm{KCl}$ 基质, 随后 $600{ }^{\circ} \mathrm{C}$ 热 退火得到有序结构, 平均粒径为 $2 \mathrm{~nm}$ 。 $\mathrm{KCl}$ 是反应 过程中的不溶性副产物, 可以有效捕获纳米晶, 抑 制其在退火过程中的团聚。另外, 通过控制退火时 间/温度以及金属前驱体和 $\mathrm{KCl}$ 的比例还可以调控

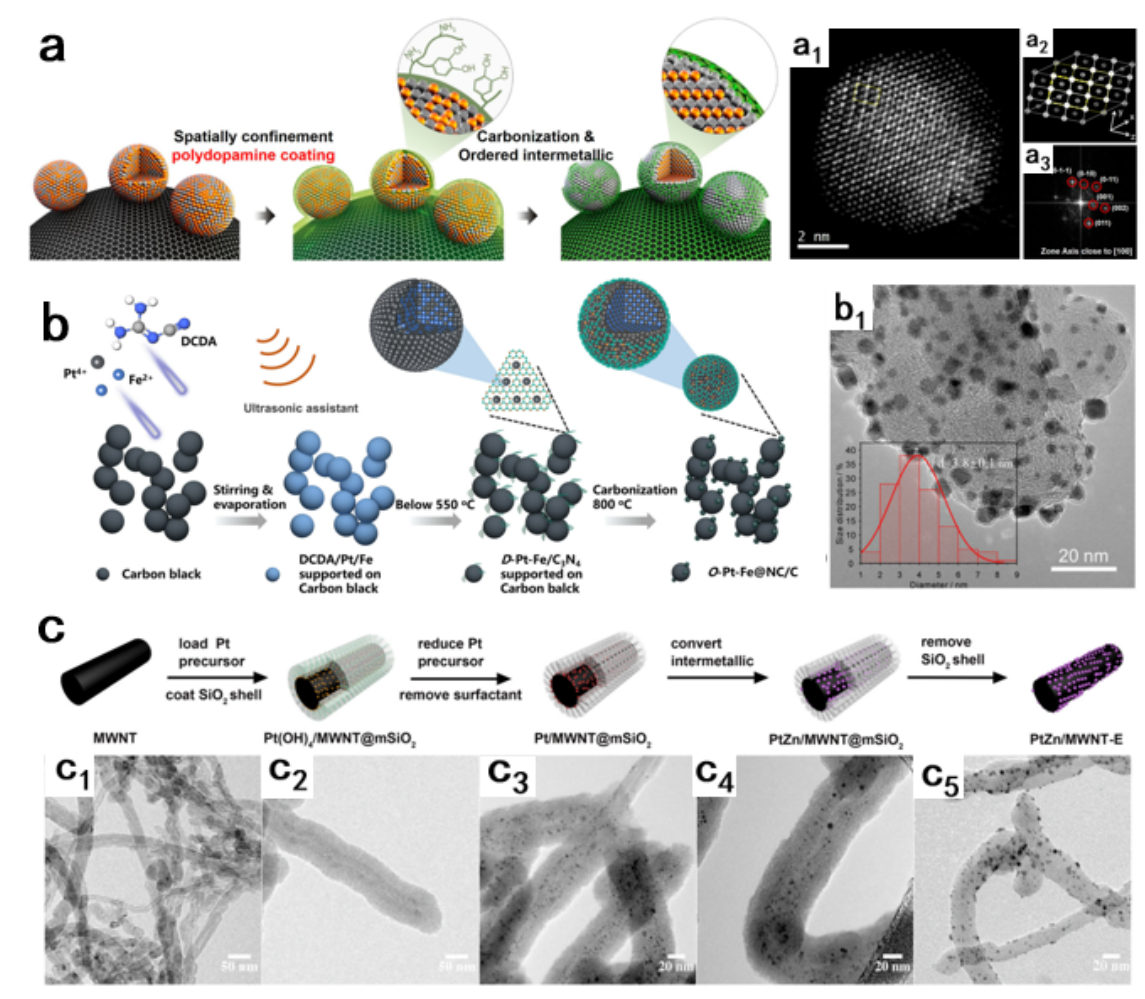

图6 (a)有序fct-PtFe/C催化剂的合成示意图以及HADDF-STEM图像( $\left.a_{1} 、 a_{3}\right) 、$ 模型图(a $a_{2}{ }^{14}$; (b) O-PtFe $@ N C / C$ 纳米晶的合成示意图和TEM图像 $\left(\mathrm{b}_{1}\right)^{78}$; (c) PtZn/MWNT@ $9 \mathrm{mSiO}_{2}$ 的合成示意图和TEM图像 ${ }^{80}$

Fig. 6 (a) Synthesis schematic, HAADF-STEM images $\left(a_{1}, a_{3}\right)$ and model structure(a $\left(a_{2}\right)$ of ordered fct-PtFe/C nanoparticles ${ }^{14}$; (b) synthesis schematic of $\mathrm{O}-\mathrm{Pt}-\mathrm{Fe} @ \mathrm{NC} / \mathrm{C}$ nanoparticles and the overview TEM image $\left(\mathrm{b}_{1}\right){ }^{78}$; (c) synthesis schematic and TEM images of PtZn/MWNT@ $\mathrm{mSiO}_{2}{ }^{80}$. (a, c) Adapted from American Chemical Society Publisher. (b) Adapted from Elsevier Publisher. 
纳米晶的颗粒大小。后作者通过原位扫描透射电 子显微镜 $(\mathrm{STEM})$ 跟踪了退火过程中有序 $\mathrm{PtFe}$ 纳米 晶在 $\mathrm{KCl}$ 基质中的生长过程 84 , 再次验证了将纳米 晶包裹在 $\mathrm{KCl}$ 基质中可以显著减缓团聚, 抑制颗粒 增长。一般来说, 在纳米晶生长过程中存在两种竞 争机制: 奥斯特瓦尔德熟化和聚结。奥斯特瓦尔德 熟化是由原子交换引起的, 伴随着大颗粒变更大、 小颗粒变更小的过程。而聚结是纳米颗粒自身运 动的结果。作者在原位退火研究中发现纳米晶的 生长机制主要是纳米颗粒自身运动发生的聚结。 $\mathrm{Cui}$ 等 ${ }^{85}$ 同样采用这种方法, 用三乙基硼氢化钾 $\left(\mathrm{KEt}_{3} \mathrm{BH}\right)$ 做还原剂还原 $\mathrm{Pd} 、 \mathrm{~Pb}$ 前驱体, 再经 $400{ }^{\circ} \mathrm{C}$ 热退火 $12 \mathrm{~h}$ 得到有序 $\mathrm{Pd}_{3} \mathrm{~Pb}$ 纳米晶, 粒径为 $5.2 \pm 0.4$ $n m 。 H R T E M$ 图像和XRD图谱表明, 所制备的 $\mathrm{Pd}_{3} \mathrm{~Pb}$ 为有序结构。Disalvo等 ${ }^{86}$ 通过 $\mathrm{KCl}$ 基质法制备了三 元有序金属间化合物 $\mathrm{Pt}_{2} \mathrm{FeCo} 、 \mathrm{Pt}_{2} \mathrm{FeNi}$ 和 $\mathrm{Pt}_{2} \mathrm{CoNi}$ 纳米晶, 证明了这种方法的普适性。但是由于 $\mathrm{KCl}$ 基质不能在每个纳米晶周围形成致密的壳层, 在 稳定纳米晶抗团聚/烧结方面效果较差 ${ }^{84,87}$ 。

\subsection{3 引入缺陷}

为了促进金属原子间的相互扩散, 可以通过 引入缺陷来降低原子扩散势垒, 实现由无序到有
序的完全转变, 目前主要是通过产生氧空位或者 引入第三种元素在纳米晶内部引入缺陷。

Sun等 88 通过控制 $\mathrm{Fe}(\mathrm{CO})_{5}$ 的分解和 $\mathrm{Pt}(\mathrm{acac})_{2}$ 的 还原, 制备了哑铃状无序 fcc-FePt- $\mathrm{Fe}_{3} \mathrm{O}_{4}$ 纳米晶, 后 续进行 $\mathrm{MgO}$ 包覆, 热退火得到了完全有序的 fct$\mathrm{FePt}$ 纳米晶。 $\mathrm{Fe}_{3} \mathrm{O}_{4}$ 还原为 $\mathrm{Fe}$ 的过程中可以产生氧 空位, 降低原子扩散势垒, 促进 $\mathrm{Fe} / \mathrm{Pt}$ 有序排列。后 来同组人员通过在 $\mathrm{FePd}$ 外生长 $\mathrm{Fe}_{3} \mathrm{O}_{4}$ 得到了海胆 形 $\mathrm{FePd}-\mathrm{Fe}_{3} \mathrm{O}_{4}, 500{ }^{\circ} \mathrm{C}$ 热退火制备了有序 $\mathrm{L} 1_{0}-\mathrm{FePd}$ 纳米晶 ${ }^{89}$ (图7a)。 $\mathrm{Li}$ 等 ${ }^{90}$ 采用双功能核/壳 $\mathrm{Pt} / \mathrm{NiCoO}_{x}$ 作为前驱体制备了亚 $6 \mathrm{~nm}$ 单分散有序的 $\mathrm{L} 1_{0^{-}}$ $\mathrm{PtNi}_{0.8} \mathrm{Co}_{0.2}$ 纳米晶, $\mathrm{NiCoO}_{x}$ 不仅可以提供丰富的 氧空位, 促进 $\mathrm{Pt} / \mathrm{Ni} / \mathrm{Co}$ 原子的扩散, 而且可以作为 保护壳层抑制纳米晶在热退火过程中的烧结。 Zhang等 ${ }^{91}$ 通过使用 $\mathrm{Fe}(\mathrm{CO})_{5}$ 做还原剂还原 $\mathrm{Pt}(\mathrm{acac})_{2}$ 和 $\mathrm{HAuCl}_{4} \cdot x \mathrm{H}_{2} \mathrm{O}$ 得到无序 $\mathrm{fcc}-\mathrm{FePtAu}$ 纳米晶, 后 $600^{\circ} \mathrm{C}$ 退火使其有序化, 得到壳层富 $\mathrm{Au}$ 的有序 fct$\mathrm{FePtAu}$ 纳米晶(图7b)。在退火过程中, 由于 $\mathrm{Au}$ 表面 能较低, 容易从FePtAu结构中偏析到表面, 促进 $\mathrm{FePtAu}$ 中产生晶格空位, 促使 $\mathrm{Fe} / \mathrm{Pt}$ 重排。但是加 入 $\mathrm{Au}$ 的量需要控制, 加入 $20 \%$ (原子比)的 $\mathrm{Au}$ 有利 于形成有序结构, 但添加更多的 $\mathrm{Au}(32 \%)$ 反而会

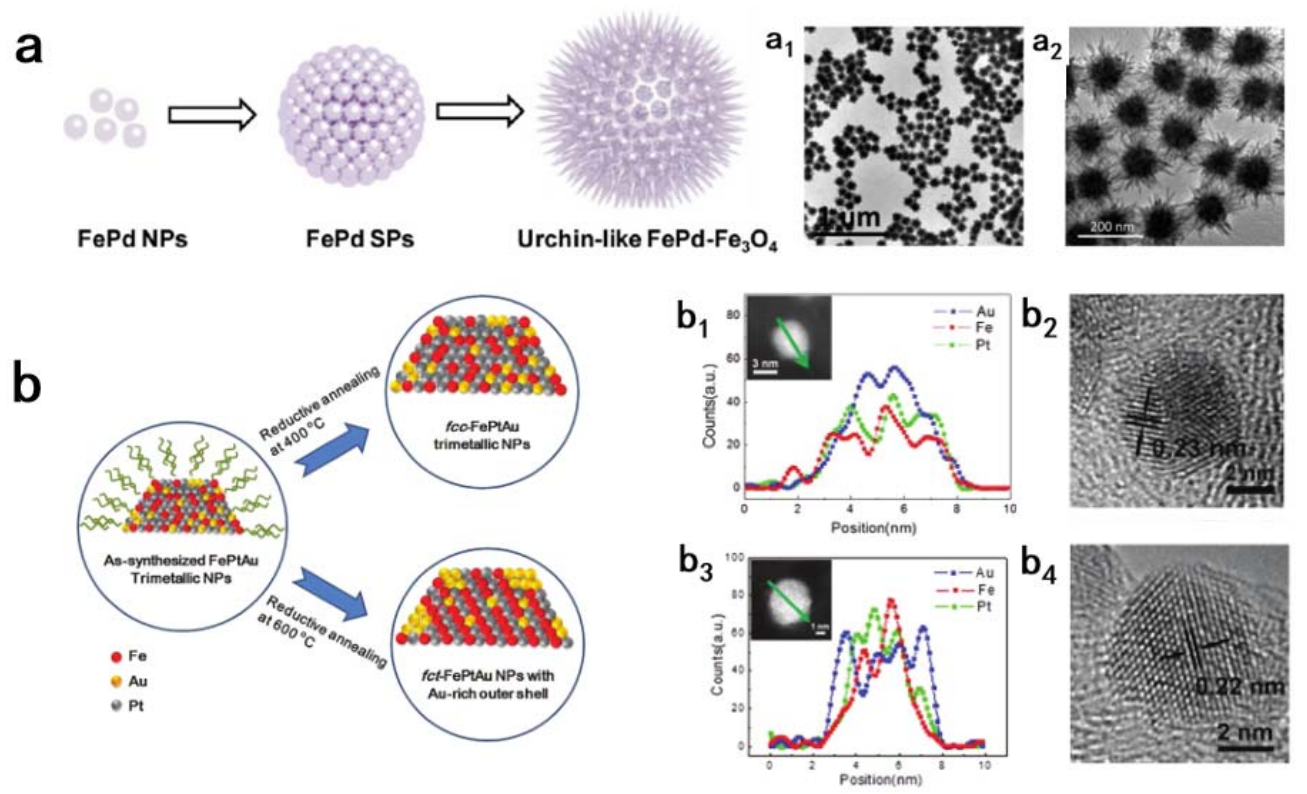

图7 (a) FePd纳米晶自团聚成 $\mathrm{FePd}$ 颗粒并形成海胆型 $\mathrm{FePd}_{2} \mathrm{Fe}_{3} \mathrm{O}_{4}$ 的示意图; $\left(\mathrm{a}_{1} 、 \mathrm{a}_{2}\right)$ 海胆型 $\mathrm{FePd}_{2} \mathrm{Fe}_{3} \mathrm{O}_{4}$ 的 $\mathrm{TEM}$ 图谱 ${ }^{89}$;

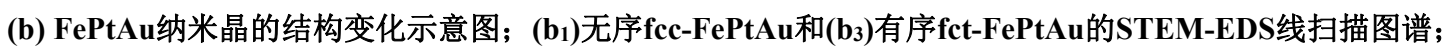

(b2)无序fcc-FePtAu和(b4)有序fct- FePtAu的TEM图像91

Fig. 7 (a) Synthesis schematic of FePd nanoparticles(NPs) self-aggregate into FePd superparticles(SPs) and the formation of urchin-like $\mathrm{FePd}_{-} \mathrm{Fe}_{3} \mathrm{O}_{4}$, (a1, a $)$ TEM images of the urchin-like $\mathrm{FePd}_{2} \mathrm{Fe}_{3} \mathrm{O}_{4}{ }^{89}$; (b) schematic diagram of the structural change of the FePtAu NPs; STEM-EDS line scans crossing fcc-FePtAu (b1) and fet-FePtAu (b3);

TEM images of fcc-FePtAu $\left(b_{2}\right)$ and fct-FePtAu $\left(b_{4}\right){ }^{91}$. 
抑制从fcc到fct的转变。另外, Kuttiyiel等 92 发现 $\mathrm{Au}$ 原子的加入同样可以促进 $\mathrm{PdCo}$ 纳米晶在高温下的 结构有序化, 掺杂 $\mathrm{Au}$ 后 $800{ }^{\circ} \mathrm{C}$ 下热退火即可得到 有序 $\mathrm{PdCo}$ 纳米晶。 $\mathrm{Yan}$ 等 ${ }^{93}$ 在无序 $\mathrm{fcc}-\mathrm{PtFe}$ 中加入 少量 $\mathrm{Sb}, \mathrm{Sb}$ 的引入也可以产生空位, 降低结构有 序化温度 $\left(550^{\circ} \mathrm{C} \rightarrow 400^{\circ} \mathrm{C}\right)$ 。类似地, 通过这种 方法制备了其他过渡金属 (M) 掺杂的有序 FePtM (如 $\mathrm{M}=\mathrm{Cu}, \mathrm{Ag}$ ) 纳米晶 ${ }^{94,95}$ 。在这些三元合金结构 中, Pt和 $\mathrm{Fe}$ 之间的相互作用较强, 而Pt、Fe与 $\mathrm{M}$ 的 相互作用均较弱, 热退火过程中, $\mathrm{M}$ 会被挤到纳米 晶的表面, 从而在纳米晶内部留下空位, 促进原子 的迁移。

\section{2 直接液相合成法}

直接液相合成法可以在相对较低的温度 $(<$ $\left.350^{\circ} \mathrm{C}\right)$ 下, 通过在溶液中加入前驱体、还原剂、封 端剂和表面活性剂等直接合成金属间化合物, 而 不需要高温退火, 避免了退火过程中的颗粒团聚。 由于溶剂沸点的限制, 反应只能在低于溶剂的相 转变温度下进行, 可能导致无序到有序相的部分 转化, 故采取合适的策略以降低无序-有序转变势 垒至关重要。可采取的策略为: (1)在反应溶液中 加入卤化物离子或抗坏血酸以减缓晶体生长速 度; (2)利用种子介导合成法, 首先合成具有明确 尺寸、形状和成分的金属纳米晶种子, 再扩散生长 将第二种金属扩散到合成的种子中。

$\mathrm{Li}$ 等 96 采用 $\mathrm{Pt}(\mathrm{acac})_{2} 、 \mathrm{SnCl}_{2} \cdot 2 \mathrm{H}_{2} \mathrm{O}$ 作为金属前 驱体, 聚乙烯吡咯烷酮(PVP) 作为表面活性剂, $\mathrm{N}, \mathrm{N}$-二甲基甲酰胺(DMF) 作为溶剂和还原剂, 通过 $\mathrm{SnCl}_{2}$ 在反应过程中释放的 $\mathrm{Cl}^{-}$减缓晶体生长, 并协 同 $\mathrm{O}_{2}$ 对纳米晶产生刻蚀, 合成了立方体 $\mathrm{Pt}_{3} \mathrm{Sn}_{\text {金属 }}$ 间化合物。将前驱体浓度增加到原来的 2 倍和 8 倍 时, 分别得到了轻微腐蚀和严重腐蚀的凹形 $\mathrm{Pt}_{3} \mathrm{Sn}$ 立方体; 另外, 当还原过程在无 $\mathrm{O}_{2}$ (饱和 $\mathrm{N}_{2}$ 或饱和 $\mathrm{CO}$ )的DMF溶液中进行时, 只能得到表面没有缺 陷的 $\mathrm{Pt}_{3} \mathrm{Sn}$ 立方体。根据Tilley报道的生长-腐蚀协 同生长机理 ${ }^{97}$, 在较高浓度腐蚀剂存在的条件下, 腐蚀过程与生长过程同步进行。 $\mathrm{Sn}$ 是亲氧元素, 在 反应开始时, 还原的 $\mathrm{Sn}$ 原子被还原的 $\mathrm{Pt}$ 原子和 $\mathrm{O}_{2}$ 分子包围。当一个 $\mathrm{Sn}$ 原子被还原时, 两个 $\mathrm{Cl}^{-}$被释 放到溶液中, 而卤素离子和 $\mathrm{O}_{2}$ 是贵金属在溶液中 常见的腐蚀剂。因此, 开始时因 $\mathrm{Cl}^{-}$浓度较低, 刻 蚀过程缓慢。随着 $\mathrm{Sn}$ 原子的还原, 更多的 $\mathrm{Cl}^{-}$释放 到溶液中, 导致刻蚀速率加快, 形成更多的缺陷 (图 8a-e)。根据金属间化合物 $\mathrm{CuAu}$ 的扩散生长机 制 ${ }^{98}$, 新生成的 $\mathrm{Sn}$ 原子可以从表面扩散到富 $\mathrm{Pt}$ 晶种 的晶格中, 形成PtSn固溶体。反应釜中的高温高压

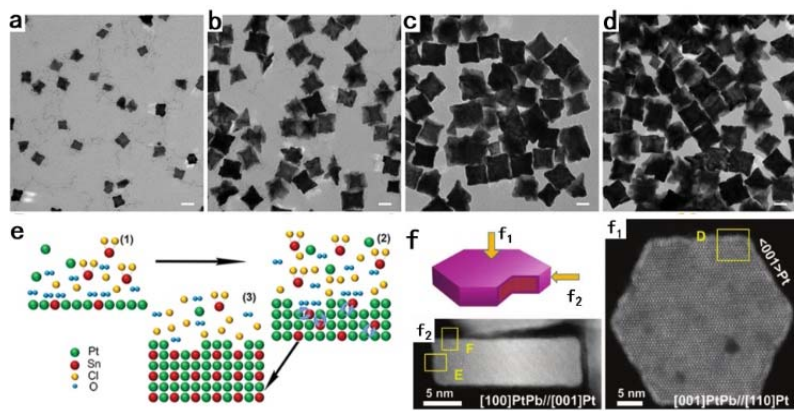

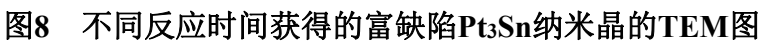

像: (a) $1 \mathrm{~h}$ ，(b) $1.5 \mathrm{~h}$ ，(c) $2 \mathrm{~h}$ ，(d) $6 \mathrm{~h}$; (e)表面富缺陷的 $\mathrm{Pt}_{3} \mathrm{Sn}$ 形成原理图 ${ }^{96}$; (f) PtPb/Pt纳米板的模型图以及 HAADF-STEM图像99

Fig. 8 TEM images of defect-rich $\mathrm{Pt}_{3} \mathrm{Sn}$ nanoparticles obtained at different reaction time: (a) $1 \mathrm{~h}$, (b) $1.5 \mathrm{~h}$,

(c) $2 \mathrm{~h}$, (d) $6 \mathrm{~h}$; (e) the formation schematic of defect-rich $\mathrm{Pt}_{3} \mathrm{Sn}^{96}$; (f) the model and HAADF-STEM images of $\mathrm{PtPb} / \mathrm{Pt}$ nanoplate ${ }^{99}$.

(a-e) Adapted from American Chemical Society Publisher. (f) Adapted from

The American Association for the Advancement of Science Publisher.

环境为有序化提供了足够的能量, 最终形成了表 面缺陷较多的金属间化合物纳米晶。这种动力学 控制和刻蚀辅助的方法也可以扩展到合成其他富 缺陷和凹面纳米立方体金属间化合物。

金属前驱体、还原剂、封端剂、表面活性剂等 各种因素可以影响晶体生长过程中的热力学和动 力学, 从而对纳米晶的形貌进行控制。Huang等 99 利用 $\mathrm{Pt}(\mathrm{acac})_{2} 、 \mathrm{~Pb}(\mathrm{acac})_{2}$ 作为前驱体, 抗坏血酸作 为还原剂, 油胺和十八烯作为混合溶剂和表面活 性剂, 制备了有序 $\mathrm{PtPb} / \mathrm{Pt}$ 六方核壳纳米片(图8f)。 利用种子介导的扩散生长, 制备过程包括Pt物种 的还原以及随后的互扩散形成结构有序的 $\mathrm{PtPb}$ 纳 米片。实验表明使用抗坏血酸作为还原剂是形成 $\mathrm{Pt}$ 壳的关键, 其作为弱酸可以去除 $\mathrm{Pb}$, 使表层的 $\mathrm{Pt}$ 原子在高温下扩散和重排, 用葡萄糖、柠檬酸等其 他还原剂取代抗坏血酸则不能制得最终产物。Qin 等 ${ }^{100}$ 以 $\mathrm{Pt}(\mathrm{acac})_{2} 、 \mathrm{Bi}(\mathrm{ac})_{3}$ 为前驱体, 抗坏血酸为还 原剂, 十八烯和油胺为溶剂, $\mathrm{NH}_{4} \mathrm{Br}$ 为封端剂, 制 备了 $\mathrm{PtBi} / \mathrm{Pt}$ 六方核壳结构纳米片, $\mathrm{Br}^{-}$可以选择性 地吸附在纳米晶的不同晶面上, 从而引导纳米晶 的各向异性生长, 产生所需形貌。另外, 作者用 $\mathrm{Mo}(\mathrm{CO})_{6}$ 提供 $\mathrm{CO}$, 作为封端剂, 只能得到 $\mathrm{PtBi}$ 立方 体; 改变抗坏血酸的浓度或使用还原性较弱的苯 胺, 也不能得到纳米片。由此可见, 纳米晶的形貌 与前驱体、还原剂、溶剂、封端剂、表面活性剂的 选择密切相关。 
表1 本文综述的Pt/Pd基有序金属间化合物催化剂合成方法及应用

Table 1 Summary of Pt and Pd-based ordered intermetallic nanocatalysts with corresponding synthetic approaches and applications hightlighted in this report.

\begin{tabular}{|c|c|c|c|c|c|}
\hline Synthetic method & Composition & Reaction temperature $/{ }^{\circ} \mathrm{C}$ & Application & Particle size/nm & Ref. \\
\hline \multirow[t]{8}{*}{ Annealing with support } & $\mathrm{Pt}_{3} \mathrm{Co}$ & 700 & ORR & 7.2 & 16 \\
\hline & $\mathrm{PtPb}$ & 700 & FAOR & 42.4 & 60 \\
\hline & PtBi & 600 & FAOR & $2-3.5$ & 47 \\
\hline & $\mathrm{Pd}_{3} \mathrm{Fe}$ & 750 & FAOR & 11 & 62 \\
\hline & $\mathrm{PtFe}$ & 650 & ORR & 6 & 63 \\
\hline & $\mathrm{Pt}_{3} \mathrm{Co}$ & 900 & ORR & 3 & 66 \\
\hline & $\mathrm{Fe}_{3} \mathrm{Pt}$ & 900 & ORR & $1-4$ & 67 \\
\hline & $\mathrm{CePt}_{5}$ & 900 & - & 8 & 72 \\
\hline \multirow[t]{8}{*}{ Annealing with coating } & $\mathrm{PtFe}$ & 700 & ORR & 6.5 & 13 \\
\hline & $\mathrm{PtFe}$ & 800 & ORR & 3.8 & 74 \\
\hline & $\mathrm{PdFe}$ & 800 & ORR & - & 75 \\
\hline & $\mathrm{PtZn}$ & 600 & MOR & 2.1 & 77 \\
\hline & $\mathrm{Pd}_{2} \mathrm{FeCo}$ & 500 & ORR & 6.5 & 78 \\
\hline & $\mathrm{FePt}$ & 800 & - & 7 & 79 \\
\hline & $\mathrm{Pt}_{3} \mathrm{Fe}$ & 600 & - & 2 & 80 \\
\hline & $\mathrm{Pd}_{3} \mathrm{~Pb}$ & 400 & ORR & 5.2 & 82 \\
\hline \multirow[t]{4}{*}{ Annealing with defects } & $\mathrm{FePd}$ & 500 & - & 6 & 86 \\
\hline & $\mathrm{PtNi}_{0.8} \mathrm{Co}_{0.2}$ & 600 & ORR & 6 & 87 \\
\hline & $\mathrm{FePtAu}$ & 600 & FAOR & 4 & 88 \\
\hline & AuPdCo & 800 & ORR & 6.7 & 89 \\
\hline \multirow[t]{3}{*}{ Solution phase synthesis } & $\mathrm{Pt}_{3} \mathrm{Sn}$ & 180 & - & $12.8 / 22.8 / 18.3$ & 93 \\
\hline & $\mathrm{PtPb}$ & - & - & 16 (edge length) & 96 \\
\hline & $\mathrm{PtBi}$ & 160 & - & 2.5 (thickness) & 97 \\
\hline
\end{tabular}

通过直接液相合成法可以合成不同形貌的金 属间化合物纳米晶, 提升其比表面积, 暴露高活性 晶面以提高催化活性, 但合成过程中复杂的动力 学以及热力学过程仍不是十分清楚, 可重复性较 差, 难以实现规模化制备。另外, 所加入的封端剂 和表面活性剂极易吸附在材料表面, 后续的去除 较为困难和繁琐, 因此液相合成法直接得到有序 金属间化合物策略还需进一步地研究和探索。

\section{4 在PEMFCs中的电催化应用}

\section{1 氧还原反应(ORR)}

在PEMFCs的各种电催化反应中, 由于阴极 ORR动力学速率远慢于阳极小分子氧化反应, 使 得PEMFCs运行过程中有很大的过电位差, 导致功 率密度下降, 从而抑制燃料电池的商业化应用, 故 ORR 是目前研究最广泛的一个反应。另外, ORR发 生的电位(1.23 Vvs. SHE)较高, 催化剂可能会在高 电位下发生溶解, 难以稳定存在, 同样限制着燃料
电池的发展。研究发现最佳氧吸附能 $\left(\Delta E_{0}\right)$ 对 $\mathrm{ORR}$ 活性至关重要, 活性与 $\Delta E_{0}$ 之间呈现火山型关系。 对于 $\operatorname{Pt}(111)$ 晶面, 当 $\Delta E_{0}$ 为 $-0.2 \mathrm{eV}$ 时具有最佳 $\mathrm{ORR}$ 催化活性 ${ }^{101}$ 。将过渡金属与 $\mathrm{Pt} / \mathrm{Pd}$ 合金化, 制备核 壳结构的纳米晶, 通过应变效应和电子效应可以 调节 $\mathrm{Pt} / \mathrm{Pd}$ 的 $d$ 带中心、降低氧吸附能, 提升催化剂 的活性与选择性 ${ }^{102}$ 。 Markovic 等 ${ }^{101}$ 证明了 $\mathrm{Pt}_{3} \mathrm{Ni}$ (111) 晶面比相应的 $\mathrm{Pt}(111)$ 晶面的ORR活性高 10 倍, 比商业 $\mathrm{Pt} / \mathrm{C}$ 催化剂的活性高90倍。另外, $\mathrm{Pt} / \mathrm{Pd}$ 与过渡金属 $\mathrm{M}$ 之间强烈的 $d-d$ 轨道相互作用可以 稳定 $\mathrm{M}$, 抑制其在长循环过程中的浸出, 有效提升 催化剂的稳定性。有序金属间化合物相比于无序 合金, 电子效应和应变效应将进一步加强, 具有更 优异的活性与稳定性。

表面应变能有效提升核壳结构电催化剂的 ORR活性。以金属间化合物为内核, $\mathrm{Pt}$ 单质或 $\mathrm{Pt}$ 合 金为外壳的核壳结构电催化剂由于电子转移和晶 格错配, 产生了配体效应和应变效应, 能有效促进 
ORR的进行。另外, Pt壳可以有效抑制内部过渡金 属的溶解, 提升材料的稳定性。王得丽课题组 ${ }^{17}$ 通 过浸渍还原法制备了核壳结构 $\mathrm{Pt}_{3} \mathrm{Co} @ \mathrm{Pt}$ 有序金属 间化合物, 具有2-3个原子层厚的Pt壳(图9a)。在0.1 $\mathrm{mol} \cdot \mathrm{L}^{-1} \mathrm{HClO}_{4}$ 电解液中进行电化学测试, $0.9 \mathrm{~V}(\mathrm{vs}$. $\mathrm{RHE}$ )时 $\mathrm{MA}$ 为 $0.52 \mathrm{~A} \cdot \mathrm{mg}^{-1}$, 与 $\mathrm{Pt} / \mathrm{C}$ 相比, $\mathrm{MA}$ 提高 了 $200 \%$ 以上, SA提高了 $300 \%$ 以上(图9e)。另外, 5000 周稳定性测试发现材料半波电位衰减小于 10 $\mathrm{mV}$, 通过透射电镜观察到材料内部依然为有序结 构, 展现出极优异的活性与稳定性(图9f), 这归因 于富 $\mathrm{Pt}$ 的壳层以及有序排列的 $\mathrm{Pt}_{3} \mathrm{Co}$ 内核与 $\mathrm{Pt}$ 壳之 间的压缩应变优化了 Pt的电子结构, 从而降低了 对含氧物种的吸附能。类似地, 通过浸渍还原法和 后续自发置换制备了核壳结构 $\mathrm{Pd}_{3} \mathrm{~V} @ \mathrm{Pt}$ 有序金属 间化合物 ${ }^{103}$, 通过元素 mapping图看到了 Pt壳的 存在。 $\mathrm{Pd}_{3} \mathrm{~V} @ \mathrm{Pt} / \mathrm{C}$ 的半波电位与 $\mathrm{Pt} / \mathrm{C}$ 相当, 具有比 $\mathrm{Pd} / \mathrm{C}$ 更高的ORR电催化活性, 且在10000周稳定性 测试后无明显衰减(图9g)。另外, 将Pt壳修饰的 $\mathrm{PdFe} @ \mathrm{Pt} / \mathrm{C}$ 有序金属间化合物 ${ }^{31}$ (图9h) 用于锌空电 池, 功率密度为 $293 \mathrm{~mW} \cdot \mathrm{cm}^{-2}$, 电流密度为 342 $\mathrm{mA} \cdot \mathrm{cm}^{-2}$, 远高于 $\mathrm{Pt} / \mathrm{C}$ 催化剂, 且可以连续放电 87 $\mathrm{h}$ 。DFT计算表明, 氧在O-PdFe@Pt(111)面的吸附 能 $\left(\Delta E_{0}\right)$ 比在 $\operatorname{Pt}(111)$ 面的低 $0.2 \mathrm{eV}$, 达到了理论上
ORR催化最佳值。我们还制备了有序PtFe@Pt催化 剂, 通过原位同步辐射(XAFS)发现优异的循环稳 定性归因于稳定有序的结构 47 。

具有Pt合金外壳的催化剂也可有效提升材料的 催化性能。 $\mathrm{Bu}$ 等 ${ }^{104}$ 制备了以 $\mathrm{PtPb}$ 金属间化合物为 内核, PtNi合金为外壳的核壳结构催化剂, 其MA 和 $S A$ 分别为 $1.92 \mathrm{~A} \cdot \mathrm{mg}^{-1}$ 和 $5.16 \mathrm{~mA} \cdot \mathrm{cm}^{-2}$, 分别约为 商业 $\mathrm{Pt} / \mathrm{C}$ 的 11 倍和 20 倍。15000次循环后, 材料的 活性几乎没有衰减, ORR活性的增强归因于核壳 结构及不同组分之间的协同效应。Wang等 ${ }^{105}$ 制备 了以 $\mathrm{PdCu}$ 金属间化合物为内核, $\mathrm{PtCu}$ 合金为外壳 的核壳结构电催化剂, 由于核壳组元之间存在较大 的结构和晶格错配, 具有极优异的活性与耐久性。

通过理论计算可以有效指导制备具有优异性 能的催化剂。庄林课题组 ${ }^{106}$ 利用密度泛函理论 (DFT)计算(图9c), 发现在 $\mathrm{AuCu}(111)$ 衬底上由 1.5 个单层 Pt组成的结构与 $\mathrm{Pt}(111)$ 相比, 氧吸附能 $\left(\Delta E_{0}\right)$ 低 $0.2 \mathrm{eV}$, 达到了最佳ORR活性吸附能。通过 用 $\mathrm{Pt}$ 取代 $\mathrm{AuCu}$ 金属间化合物纳米晶表面的 $\mathrm{Cu}$ 原 子, 得到了具有小于两个原子层 $\mathrm{Pt}$ 壳的 $\mathrm{Pt}^{\mathrm{S}} \mathrm{AuCu}$, 应 用XAFS 和HAADF-STEM对其进行表征，发现60\% 以上的 $\mathrm{Pt}$ 原子偏聚在纳米晶的外表面, 大大提高 了 $\mathrm{Pt}$ 原子的利用率。 $\mathrm{Pt}^{\mathrm{S}} \mathrm{AuCu}$ 金属间化合物纳米晶
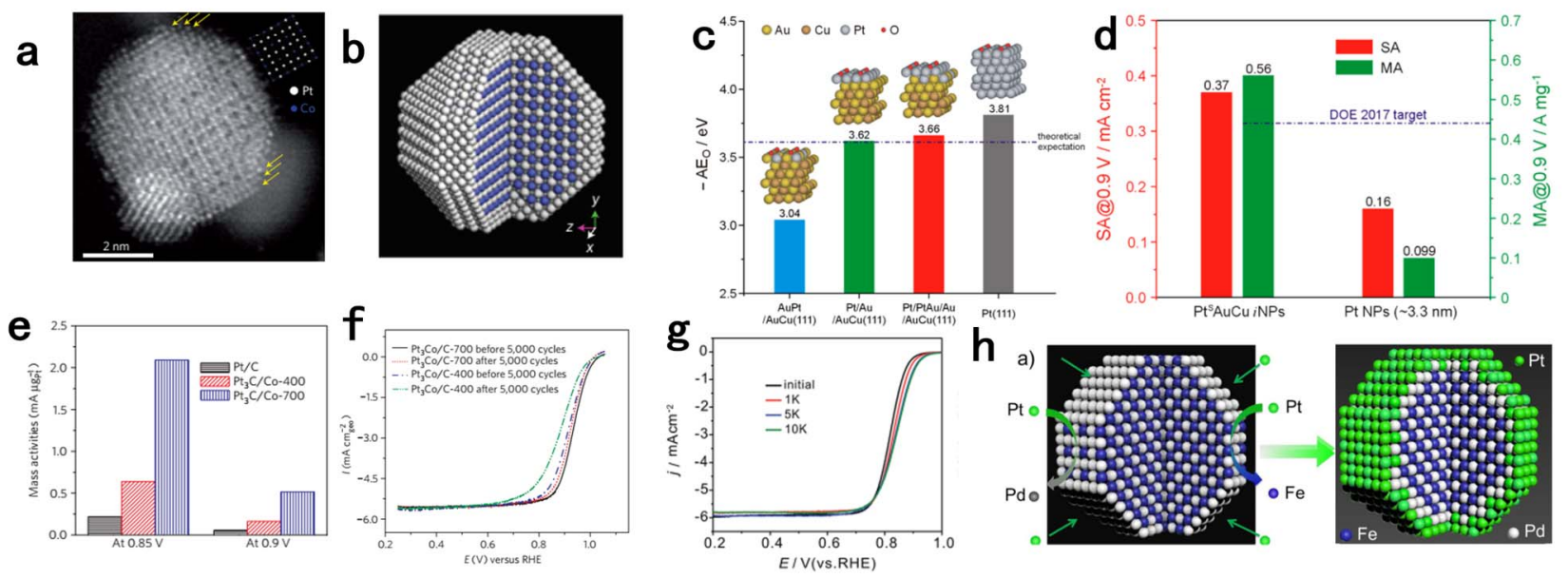

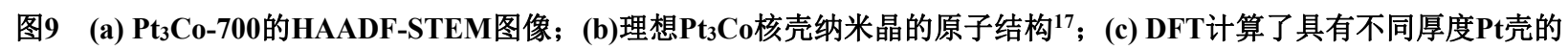

$\mathrm{AuCu}(111)$ 表面的氧吸附能 $\left(\Delta E_{0}\right)$; (d) $0.9 \mathrm{~V}$ (vs. RHE)时 $\mathrm{Pt}^{\mathrm{s}} \mathrm{AuCu}$ 催化剂与 Pt催化剂的SA和MA ${ }^{106}$; (e)比较 $\mathrm{Pt} / \mathrm{C}$ 、 $\mathrm{Pt}_{3} \mathrm{Co} / \mathrm{C}-400$ 和 $\mathrm{Pt}_{3} \mathrm{Co} / \mathrm{C}-700$ 在 0.85 和 $0.9 \mathrm{~V}$ 时的 $\mathrm{MA}$; (f) 比较 $\mathrm{Pt}_{3} \mathrm{Co} / \mathrm{C}-400$ 和 $\mathrm{Pt}_{3} \mathrm{Co} / \mathrm{C}-700$ 在 5000 个电位循环前后的 ORR活性 ${ }^{17}$; (g) 不同电位循环次数下Pd $3 \mathrm{~V} @ P t / C$ 的ORR极化曲线 ${ }^{103} ;(\mathrm{h}) \mathrm{O}-\mathrm{PdFe}$ 向O-PdFe@Pt转变示意图 ${ }^{31}$

Fig. 9 (a) HAADF-STEM image of $\mathrm{Pt}_{3} \mathrm{Co} / \mathrm{C}-700$; (b) the ideal structure of $\mathrm{Pt}_{3} \mathrm{Co}_{0}$ core-shell nanoparticle ${ }^{17}$; (c) DFT calculated the oxygen adsorption energy $\left(\Delta E_{0}\right)$ for $\mathrm{AuCu}(111)$ with different thickness of $\mathrm{Pt}$ shell; (d) $\mathrm{SA}$ and $\mathrm{MA}$ of $\mathrm{Pt} \mathrm{s}^{\mathrm{s}} \mathrm{AuCu}$ and $\mathrm{Pt}$ nanoparticles at $0.9 \mathrm{~V}{ }^{106}$; (e) the $\mathrm{MA}$ of $\mathrm{Pt} / \mathrm{C}, \mathrm{Pt}_{3} \mathrm{Co} / \mathrm{C}-400$ and $\mathrm{Pt}_{3} \mathrm{Co} / \mathrm{C}-700$ at 0.85 and $0.9 \mathrm{~V}$; (f) ORR polarization curves of $\mathrm{Pt}_{3} \mathrm{Co} / \mathrm{C}-400$ and $\mathrm{Pt}_{3} \mathrm{Co} / \mathrm{C}-700$ before and after 5000 potential cycles ${ }^{17} ;(\mathrm{g}) \mathrm{ORR}$ polarization curves of $\mathrm{Pd}_{3} \mathrm{~V} @ \mathrm{Pt} / \mathrm{C}^{103}$; (h) schematic diagram of the transformation from O-PdFe to O-PdFe@Pt ${ }^{31}$. 
对 ORR 的 MA 达到了0.56 A.mg-1@0.9V (vs. $\mathrm{RHE})$, 是 $\mathrm{Pt} / \mathrm{C}$ 的 5 倍多, 而且远超美国能源部制定 的 2017 年ORR催化剂目标 $\left(0.44 \mathrm{~A} \cdot \mathrm{mg}^{-1} @ 0.9 \mathrm{~V}\right.$ (vs. RHE)) (图9d)。Sun等 ${ }^{107}$ 通过DFT计算预测了具有 0.8 和 $1.2 \mathrm{~nm} \mathrm{CuPd}_{2}$ 壳层的 $\mathrm{M} / \mathrm{CuPd}(\mathrm{M}=\mathrm{Ag}, \mathrm{Au})$ 纳 米晶具有催化ORR最佳的表面应变和组成。在 $\mathrm{Ag}$ 或 $\mathrm{Au}$ 种子存在下, 通过共还原 $\mathrm{Pd}(\mathrm{acac})_{2}$ 和 $\mathrm{Cu}(\mathrm{acac})_{2}$ 制备了单分散的 $\mathrm{M} / \mathrm{CuPd}$ 纳米晶, 壳层厚 度分别控制在 $0.4 、 0.75$ 和 $1.1 \mathrm{~nm}$, 在 $0.1 \mathrm{~mol} \cdot \mathrm{L}^{-1}$ $\mathrm{KOH}$ 溶液中进行电化学测试发现, 具有 0.75 和 1.1 $\mathrm{nm}$ 壳层的纳米晶 $\mathrm{MA}$ 高达 $0.20 \mathrm{~A} \cdot \mathrm{mg}^{-1}$, 是商业 $\mathrm{Pt}$ 的 3 倍以上。后续 $\mathrm{Sun}$ 等 ${ }^{108}$ 通过将核壳 $\mathrm{Pd} / \mathrm{Fe}_{3} \mathrm{O}_{4}$ 纳米晶 高温还原退火, 随后在乙酸中刻蚀 Fe制备了具有 不同壳层厚度 $(0.27 、 0.65$ 和 $0.81 \mathrm{~nm})$ 的 fct-FePd/Pd 纳米晶。 fct-FePd/Pd-0.65纳米晶中 Pd的晶格收缩 程度最有利于 ORR反应进行, 具有类似 $\mathrm{Pt}$ 的活性 和耐久性。调整核壳结构的表面应变和组成可以 使催化剂达到最优异的ORR性能。

具有 $\mathrm{N}$ 掺杂碳包覆层的有序纳米晶结合了有 序结构的超高稳定性、碳壳的保护作用以及 $\mathrm{N}$ 的针 定效应等多个优点, 具有优异的ORR性能。王得丽 课题组 ${ }^{78}$ 通过一步高温热解法制备了 $\mathrm{N}$ 掺杂碳壳 包覆的有序 $\mathrm{PtFe}$ 有序金属间化合物, 原位形成的 $\mathrm{N}$ 掺杂碳壳不仅有效抑制了 Pt-Fe有序金属间化合物 在热退火过程中的团聚, 而且提供了很强的针定 效应, 避免了 $\mathrm{PtFe}$ 纳米晶在电位循环过程中从碳 载体上脱落, 还可以减弱催化剂表面与毒化物种 的吸附。将其作为阴极催化剂, 组装为全电池进行 高温PEMFCs测试发现, 在 $160^{\circ} \mathrm{C}$ 下, 峰值功率密 度高达 $384 \mathrm{~mW} \cdot \mathrm{cm}^{-2}$, 具有极优异的抗毒化性能。 另外, 通过这种方法制备的 N掺杂碳壳包覆的Pd$\mathrm{Fe}$ 催化剂 ${ }^{38}$ 用于锌空电池, 展现出极为优异的电池 性能。除通过包覆方式进行 $\mathrm{N}$ 掺杂外, 在金属间化 合物内部直接进行 $\mathrm{N}$ 掺杂的材料也被成功制备。 Zhao等 ${ }^{109}$ 通过在 $\mathrm{NH}_{3}$ 中热退火制备了科琴黑 $(\mathrm{KB})$ 负载的 $N$ 掺杂核壳结构有序金属间化合物PtNiN催 化剂。其具有 $\mathrm{Ni}_{4}-\mathrm{N}$ 和 $\mathrm{Pt}$ 晶面交替的有序结构, 在 $0.1 \mathrm{~mol} \cdot \mathrm{L}^{-1} \mathrm{HClO}_{4}$ 中进行 ORR测试, 半波电位高达 $0.935 \mathrm{~V}$ ( vs. RHE), $0.9 \mathrm{~V}$ ( $v s$. RHE)下的MA和 $\mathrm{SA}$ 分 别为 $1.83 \mathrm{~A} \cdot \mathrm{mg}^{-1}$ 和 $2.92 \mathrm{~mA} \cdot \mathrm{cm}^{-2}$, 且在 30000 周循 环后MA仅衰减 $27 \%$, 达到了DOE 2020年的目标 (MA: $0.44 \mathrm{~A} \cdot \mathrm{mg}^{-1}$ ，30000周衰减< 40\%)。原位X射 线吸收光谱 $(\mathrm{XAS})$ 表示, $\mathrm{N}$ 掺杂促使了有序 $\mathrm{PtNiN} / \mathrm{KB}$ 金属间化合物的形成, 增强了其在酸性 电解液中的稳定性。DFT计算表明, 金属间化合物 相的形成和 $\mathrm{N}$ 掺杂引入的拉伸应变优化了含氧物
种在Pt表面的结合, 实现了电子的高效转移, 从而 提高了 ORR 性能。将其组装到MEA中进行测试, $0.8 \mathrm{~V}\left(v s\right.$. RHE) 时电流密度为 $348 \mathrm{~mA} \cdot \mathrm{cm}^{-2}$, 超过 了DOE的目标 $\left(300 \mathrm{~mA} \cdot \mathrm{cm}^{-2}\right)$ 。

结合形貌调控和核壳结构, 制备不同形貌和 结构的纳米晶, 可有效增强应变效应, 促进催化性 能的提升。王得丽课题组通过浸渍还原法制备了 有序 $\mathrm{Cu}_{3} \mathrm{Pt}$ 纳米晶, 后续通过电化学和化学去合 金, 分别得到了内核为 $\mathrm{Cu}_{3} \mathrm{Pt}$ 、外壳为 $\mathrm{Pt}$ 的核壳结 构 29 和含大量孔洞的海绵状无序结构催化剂 ${ }^{110}$ 。由 于表面应变和大量电化学活性中心的生成, 这两 种去合金化方法都显著提高了 ORR 的SA和MA, 且相对于 $\mathrm{Pt} / \mathrm{C}$ 具有更高的稳定性。在 5000 个电位循 环后, MA仍然在增强。后续发现通过控制电化学 去合金的参数(电位、扫速和循环周数)可以得到不 同形貌的有序 $\mathrm{Cu}_{3} \mathrm{P}$ t纳米晶, 这对寻找高活性、高 稳定性和低成本的电催化剂具有一定的指导意 义。 $\mathrm{Bu}$ 等 ${ }^{99}$ 制备了具有双轴应变的 $\mathrm{PtPb} / \mathrm{Pt}$ 纳米片 状核壳结构催化剂, $0.9 \mathrm{~V}$ ( vs. RHE)时ORR的MA 和 $\mathrm{SA}$ 分别是商业 $\mathrm{Pt} / \mathrm{C}$ 的 26.9 和 33.9 倍, 经过 50000 次加速稳定性测试后催化性能几乎没有衰减, 表 现出超高活性与稳定性。SAED和HRTEM图像表 明, 顶面和底面的 $\mathrm{Pt}$ 与 $\mathrm{PtPb}$ 核完全共格(图8f), 沿 [011]层有 $11 \%$ 的压缩应变, 沿[100]层有 $7.5 \%$ 的拉 伸应变; 边缘的Pt在 [001]方向有 $7.5 \%$ 的拉伸应变, [110]方向有 $1.0 \%$ 的压缩应变。一般认为, 在核壳 结构的催化剂中, 压缩应变可以削弱 $\operatorname{Pt}(111)$ 表面 的Pt-O结合, 提高ORR活性 ${ }^{20}$, 而低配位的表面原 子具有更强的Pt-O结合, 从而降低ORR活性 ${ }^{111}$ 。但 是作者进行DFT计算得到, 与过渡金属对Pt的压缩 应变能提高ORR活性不同, $\operatorname{Pt}(110)$ 面上的拉伸应 变可以激活低配位的表面原子,从而提高ORR活 性。Guo等 ${ }^{100}$ 制备了由金属间化合物hcp-PtBi核和 超薄fcc-Pt壳组成的六方纳米片状核壳结构催化 剂。由于 $\mathrm{Bi}$ 存在空的 $p$ 轨道, 能使 $\mathrm{Pt}$ 的 $5 d$ 轨道降低, 有效降低 $\mathrm{Pt}$ 与含氧中间体的结合能, 提高吸/脱附 的效率。其 $\mathrm{SA}$ 高达 $1.04 \mathrm{~mA} \cdot \mathrm{cm}^{-2}$, 是商业 $\mathrm{Pt} / \mathrm{C}$ 的 5.2 倍。金属间化合物相以及 $\mathrm{Pt}$ 壳层的存在使得其在 5000 次加速稳定性测试后, 电化学活性面积仍能 保留 $90 \%$ 以上。 $\mathrm{Bi}$ 的加入也可以有效提高 $\mathrm{Pt}$ 的抗 $\mathrm{CO}$ 中毒能力, 在甲醇氧化和甲酸氧化中也具有极 优异的活性。

通过DFT计算了酸性条件下在 $U=0 \mathrm{~V}$ 和 $U=$ 1.23 V时基于PtBi-Pt界面、PtBi-Pt边缘、 $\mathrm{PtBi}$ 表面 和Pt表面的ORR四电子自由能路径(图10)。ORR过 程主要是四步, 其中还原过程可以看作是加氢和 


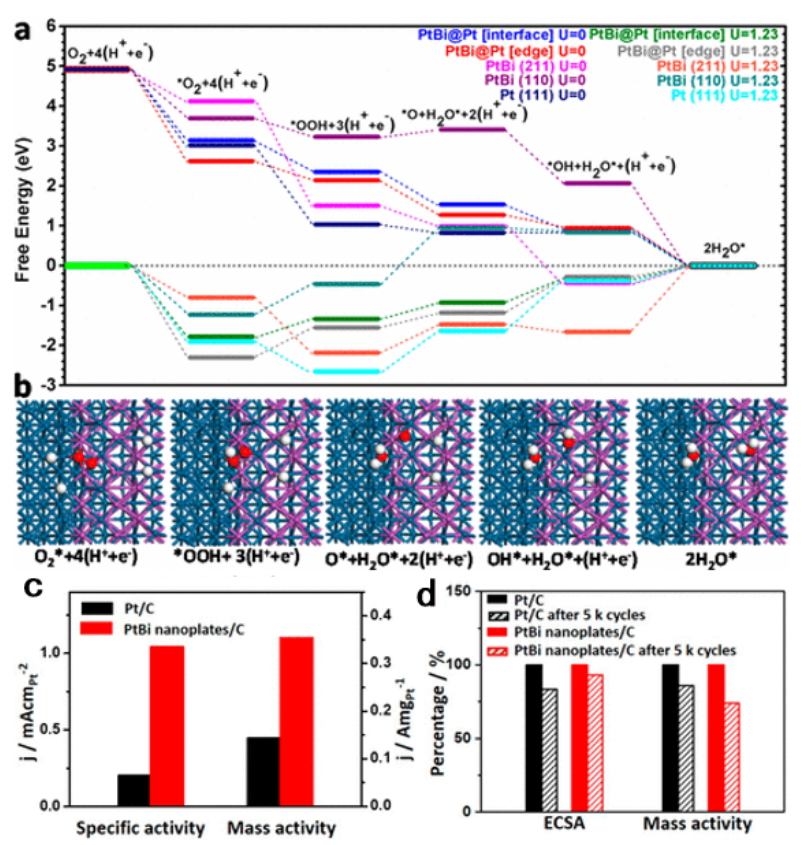

图10 (a)基于PtBi-Pt界面、PtBi-Pt边缘、PtBi(211)面、 PtBi(110)面、PtBi(111)面的酸性四电子ORR路径自由能 的比较; (b)在PtBi-Pt界面模拟ORR过程的局部结构构 型; (c) PtBi/C与 $P t / C$ 的 $S A$ 与 $M A$ 的比较; (d)起始和 5000 周循环后的 ECSA和MA ${ }^{100}$

Fig. 10 (a) Free energy pathways for acidic four-electron ORR based on the systems of PtBi-Pt interface, PtBi-Ptedge, PtBi(211) surface, PtBi(110) surface, and Pt(111) surface; (b) the local structural configurations for the simulated ORR process from the PtBi-Pt interface model system; (c) comparison of the SA and MA;

(d) comparison of ECSA and MA before and after 5000 cycles ${ }^{100}$.

Adapted from American Chemical Society Publisher.

$\mathrm{O}-\mathrm{O}$ 键断裂的过程。吸附的 ${ }^{*} \mathrm{O}_{2}$ 最初以 ${ }^{*} \mathrm{OH}$ 的形式 氢化, 然后进行 $\mathrm{O}-\mathrm{O}$ 解离为 ${ }^{*} \mathrm{O}$ 和 $\mathrm{H}_{2} \mathrm{O}^{*}$, 其中 ${ }^{*} \mathrm{O}$ 将 进一步以 ${ }^{*} \mathrm{OH}$ 的形式氢化为最终产物 $\mathrm{H}_{2} \mathrm{O}$ 。最后一 步还原 $\left.{ }^{*} \mathrm{OH}+\mathrm{H}\right] \rightarrow \mathrm{H}_{2} \mathrm{O}^{*}$ 是决速步, 在最后一次 还原中, PtBi-Pt边缘处的能量 $(0.95 \mathrm{eV})$ 比界面处的 能量 $(0.89 \mathrm{eV})$ 高出约 $0.06 \mathrm{eV}$ 。对于平坦的PtBi表 面, 高指数面(211)对 $\left[\mathrm{O}_{2}+4 \mathrm{H}\right]$ 的吸附较弱, 最后 一步将 $\mathrm{OH}$ 还原为 $\mathrm{H}_{2} \mathrm{O}$ 的势垒为 $0.43 \mathrm{eV}$ 。而 $\mathrm{PtBi}(110)$ 从 $\left[{ }^{*} \mathrm{OH}+3 \mathrm{H}\right]$ 进入 $\left.{ }^{*} \mathrm{O}+2 \mathrm{H}+\mathrm{H}_{2} \mathrm{O}\right]$ 的势垒 为 $0.19 \mathrm{eV}$ 。平均来看, PtBi-Pt纳米片比 $\mathrm{PtBi}$ 纳米晶 更有利于通过ORR生成 $\mathrm{H}_{2} \mathrm{O}$ 。

加入较稳定的金属( $\mathrm{Au} 、 \mathrm{~W}$ 等) 进行掺杂也能有 效提升催化剂的活性与稳定性。王得丽课题组 ${ }^{112}$ 制备了具有多原子层 $\mathrm{Pd}$ 壳的有序金属间化合物 $\mathrm{PdZn} / \mathrm{C}(\mathrm{O}-\mathrm{PdZn} / \mathrm{C})$, 进一步在其中掺入 $\mathrm{Au}$ 得到了
$\mathrm{Au}-\mathrm{O}-\mathrm{PdZn} / \mathrm{C}$, 相对于 $\mathrm{Pd} / \mathrm{C}$ 和 $\mathrm{Pt} / \mathrm{C}$, 其 $\mathrm{ORR}$ 的 $\mathrm{MA}$ 提 高了3倍, 且具有极优异的稳定性, 30000 次电位循 环后，MA损失小于 $10 \%$ 。活性与稳定性的提升归 因于 $\mathrm{Au}$ 原子的掺杂。Kuttiyiel等 ${ }^{113}$ 通过在PtCo 合金 中加入少量 $\mathrm{Au}$ 原子 $\left(10 \%\right.$, 原子比)制备了有序 $\mathrm{L} 1_{0}$ $\mathrm{AuPtCo}$ 金属间化合物, $\mathrm{Au}$ 的加入可以降低催化剂 中的 $\mathrm{Pt}$ 含量并作为包覆层稳定纳米晶在热退火过 程中不发生团聚。通过DFT计算发现AuPtCo-700 催化剂优异的活性与稳定性归因于 $A u$ 的晶格常数 较大, 促使 $\mathrm{Pt}$ 表面的 $d$ 带中心向费米能级移动, 减 弱了 $\mathrm{Pt}-\mathrm{O}$ 结合能。Kuttiyiel等 ${ }^{2}$ 通过在 $\mathrm{PdCo}$ 中添 加 $\mathrm{Au}$ 原子制备了有序 $\mathrm{AuPdCo}$ 催化剂, 其ORR活性 与商用 $\mathrm{Pt} / \mathrm{C}$ 相当, 但在碱性电解液中的循环稳定性 比 $\mathrm{Pt} / \mathrm{C}$ 更优异。Wang等 ${ }^{114}$ 制备了掺杂 $\mathrm{Au}$ 并包覆碳 层的有序 $\mathrm{Au}-\mathrm{PtFe}$ 纳米晶, $\mathrm{PtFe}$ 的有序结构、多孔 碳的限域作用以及 $\mathrm{Au}$ 的掺杂使得材料具有优异的 活性与稳定性, 初始 $\mathrm{SA}$ 和 $\mathrm{MA}$ 是商业 $\mathrm{Pt} / \mathrm{C}$ 催化剂的 9倍, 且在3000周循环后几乎没有衰减。Liang等 115 在 $\mathrm{PtCo}$ 晶格中引入少量金属 W (5\%-7\%, 原子比), 发现 $\mathrm{L} 1_{0}-\mathrm{W}-\mathrm{PtCo} / \mathrm{C}$ 催化剂半波电位高达 $0.953 \mathrm{~V}$ (vs. RHE), 表现出超高ORR活性与耐久性, 在0.9 $\mathrm{V}(v s . \mathrm{RHE})$ 时的 MA 与 $\mathrm{SA}$ 分别为 $2.21 \mathrm{~A} \cdot \mathrm{mg}^{-1}$ 和 $3.60 \mathrm{~mA} \cdot \mathrm{cm}^{-2}$, 远高于 $\mathrm{L} 1_{0}-\mathrm{PtCo} / \mathrm{C}(\mathrm{MA}: 1.17$ $\mathrm{A} \cdot \mathrm{mg}^{-1}, \mathrm{SA}: 1.917 \mathrm{~mA} \cdot \mathrm{cm}^{-2}$ )。另外, 将其用于 PEMFC (20\% Pt/C作为阳极)进行测试同样展现出 优异的性能, 在 $0.9 \mathrm{~V}$ 时显示了较高的初始 MA $\left(0.57 \mathrm{~A} \cdot \mathrm{mg}^{-1}\right)$, 在 30000 周循环后容量衰减 $17.5 \%$, 并在 50000 个循环后性能损失小于 $30 \%$, 达到了 DOE 2020年的目标。

通过形貌调控制备纳米框架结构材料, 可有 效提升材料的比表面积, 增加活性位点数目。 Kurungot等 116 采用溶剂热法一步合成了 $\mathrm{Cu}-\mathrm{Pt}$ 空心 纳米笼金属间化合物 (CuPt-NC), 边长大概为 20 $\mathrm{nm}$ 。这种开放式几何结构由于具有高比表面积、 很多空穴和边缘, 使得催化剂可以暴露更多的活 性位点, 提高Pt的利用率。在 $0.1 \mathrm{~mol} \cdot \mathrm{L}^{-1} \mathrm{KOH}$ 溶液 中催化ORR的MA和 SA分别为 $0.32 \mathrm{~A} \cdot \mathrm{mg}^{-1} @ 0.9 \mathrm{~V}$ (vs. RHE)和 $0.47 \mathrm{~mA} \cdot \mathrm{cm}^{-2} @ 0.9 \mathrm{~V}(v s . \mathrm{RHE})$, 分别 是 $\mathrm{Pt} / \mathrm{C}$ 的 2.9 倍和 2.5 倍。将其用于锌空电池中, 可 稳定放电 $14 \mathrm{~h}$ 。CuPt-NC优异的性能主要归因于开 放式纳米笼暴露出更多活性位点以及原子的有序 排列。王得丽课题组 ${ }^{117}$ 通过溶剂热法制备的 $\mathrm{PtCu}$ 合金纳米框架结构也具有较好的 ORR活性 (0.82 $\mathrm{A} \cdot \mathrm{mg}^{-1}$ ), 但稳定性并不理想。对其进行适当的有 序化处理得到斜方六面体结构的 $\mathrm{L}_{1}-\mathrm{PtCu}$ 金属间 化合物, 其稳定性得到大幅提升, 30000 圈循环后 
活性仅损失 $15 \%$ 。如何良好控制催化剂形貌, 设计 出兼具更多高活性晶面和优异耐久性的纳米线以 及纳米框架金属间化合物催化剂仍需要进一步研 究。

ZIF衍生碳具有高比表面积、多孔结构以及三 维骨架，在ZIF衍生碳上制备有序金属间化合物可 以限制纳米晶的增长, 提高与碳载体的接触面积 而具有良好的活性与稳定性。 $\mathrm{Wu}$ 等 ${ }^{70}$ 通过在 $\mathrm{Co}$ 掺 杂的ZIF-8 衍生碳上对 Pt纳米晶进行 $900{ }^{\circ} \mathrm{C}$ 热处理 得到有序的 $\mathrm{Pt}_{3} \mathrm{Co}$ 纳米晶。该材料的半波电位高达 $0.92 \mathrm{~V}$ ( v s. SHE), 在0.6-1.0 V之间进行稳定性测 试, 循环 30000 周后半波电位仅损失 $12 \mathrm{mV}$, 并且 结构得到了很好的保持。将其进行PEMFC性能测 试, 在 $0.8 \mathrm{~V}$ 时电流密度为 $0.27 \mathrm{~A} \cdot \mathrm{cm}^{-2}$, 略低于 $\mathrm{DOE}$ $0.3 \mathrm{~A} \cdot \mathrm{cm}^{-2}$ 的目标, 但考虑到 $\mathrm{Pt}$ 负载量 $(0.13$ $\left.\mathrm{mg} \cdot \mathrm{cm}^{-2}\right)$ 较低, $\mathrm{O}_{2}$ 浓度 $(150 \mathrm{kPa})$ 较小, 这是一个很 有发展前景的催化剂。Peng等 ${ }^{71}$ 通过热解 $\mathrm{Pt} 、 \mathrm{Fe}$ 离 子共掺杂的ZIF-8 分子篮得到了 N掺杂介孔碳负载 的 $\mathrm{Fe}_{3} \mathrm{Pt}$ 金属间化合物纳米晶, 其具有高比表面积 以及较高 $\mathrm{N}$ 掺杂量, 半波电位达 $0.884 \mathrm{~V}(v s$. RHE)。 $\mathrm{Liu}$ 等 ${ }^{118}$ 以 ZIF-8 衍生的 Fe-N-C为载体沉积 Pt纳米 晶, 热退火得到了分散在多孔Fe-N-C载体上的核 壳结构 Pt 合金有序金属间化合物纳米晶 $\left(\mathrm{Pt}_{\mathrm{A}} @ \mathrm{Fe}_{\mathrm{SA}}-\mathrm{N}-\mathrm{C}\right)$ 。该催化剂 $\mathrm{ORR}$ 半波电位高达 $0.923 \mathrm{~V}(v s . \mathrm{RHE}), \mathrm{MA}$ 在 $0.6 \mathrm{~V}$ ( $v s$. RHE) 时为 9.54 $\mathrm{A} \cdot \mathrm{mg}^{-1}$, 且具有超强耐久性, 将其经过 10000 次循 环后活度仍高达初始值的 $75.6 \%$ 。将其进行 PEMFC 性能测试, 其最大功率密度为 $1.31 \mathrm{~W} \cdot \mathrm{cm}^{-2}$, 远超 $\mathrm{Pt} / \mathrm{C}\left(0.92 \mathrm{~W} \cdot \mathrm{cm}^{-2}\right)$ 。

\section{2 阳极小分子氧化}

有机小分子阳极氧化过程中，会产生CO中间 体, 与 $\mathrm{Pt} / \mathrm{Pd}$ 有很强的结合, 会毒化反应活性位点, 使催化剂的效率急剧下降, 因此在设计催化剂时, 需要解决 CO 中毒问题 ${ }^{119}$ 。根据双功能机制, 将 $\mathrm{Pt} / \mathrm{Pd}$ 与亲氧金属结合得到无序合金或有序金属间 化合物纳米晶可有效缓解CO中毒效应 ${ }^{120}$ 。

\subsection{1 氢氧化反应 $(\mathrm{HOR})$}

$\mathrm{HOR}$ 涉及 $\mathrm{H}_{2}$ 分子中两个电子转移, 在酸性环 境中具有极快的反应动力学, $0.05 \mathrm{mg} \cdot \mathrm{cm}^{-2} \mathrm{Pt}$ 载量 即可满足商业需求。但在碱性环境下, HOR的反应 动力学慢的多, 比酸性环境中低两个数量级。碱性 环境中HOR反应的机制为: (1) Volmer: $\mathrm{H}_{2} \mathrm{O}+\mathrm{e} \rightleftharpoons$ $\mathrm{H}_{\text {ads }}+\mathrm{OH}^{-}$, (2) Tafel: $2 \mathrm{H}_{\mathrm{ads}} \rightleftharpoons \mathrm{H}_{2}$, (3) Heyrovsky: $\mathrm{H}_{2} \mathrm{O}+\mathrm{H}_{\mathrm{ads}}+\mathrm{e} \rightleftharpoons \mathrm{H}_{2}+\mathrm{OH}^{-}$。在氢电极反应中有两 种基本的反应路径: Tafel-Volmer和 HeyrovskyVolmer路径, 因为氢结合能(HBE)过强, 反应受
Volmer步骤的制约。将 $\mathrm{Fe} 、 \mathrm{Co} 、 \mathrm{Ru} 、 \mathrm{Cu} 、 \mathrm{Au}$ 等与 $\mathrm{Pt} / \mathrm{Pd}$ 进行合金化后, 由于电子效应和应变效应, 使 催化剂的 $d$ 带中心降低, 减弱氢结合能, 催化剂的 活性显著提高 ${ }^{121}$ 。另外, 大部分 $\mathrm{H}_{2}$ 是从化石燃料中 生产出来的, 里面会混杂少量 $\mathrm{CO}$ 。CO极易毒化 $\mathrm{Pt} / \mathrm{Pd}$ 催化剂表面, 影响燃料电池的性能和寿命。Pt/Pd 基合金催化剂中的亲氧金属可以在低电位下吸附 $\mathrm{OH}^{*}$ 含氧物种, 有利于氧化 $\mathrm{CO}$, 促进反应进行。

Zhuang等 122 发现在PtRu合金中 Ru的加入能影 响Pt的电子结构, 从而削弱Pt的氢结合能, 提高 $\mathrm{HOR}$ 反应动力学。 $\mathrm{PtRu}$ 合金上的峰值电流密度是 $\mathrm{Pt}$ 上的两倍, 有利于在碱中进行HOR。另外, 王得 丽课题组 ${ }^{41}$ 制备了PdFe@Pt核壳结构金属间化合 物, 在 $0.1 \mathrm{~mol} \cdot \mathrm{L}^{-1} \mathrm{KOH}$ 中测试材料的电催化性能, 通过循环伏安测试发现, 有序O-PdFe@Pt和无序 $\mathrm{D}-\mathrm{PdFe} @ \mathrm{Pt}$ 在低电位区有氢的解吸峰, 而 $\mathrm{Pt} / \mathrm{C}$ 没 有, 这说明在核壳结构中氢的吸/脱附比 $\mathrm{Pt} / \mathrm{C}$ 快。D$\mathrm{PdFe} @ \mathrm{Pt} / \mathrm{C}$ 和 $\mathrm{O}-\mathrm{PdFe} @ \mathrm{Pt} / \mathrm{C}$ 的 MA 分别 是 $\mathrm{Pt} / \mathrm{C}$ 的 1.96和7.56倍。O-PdFe@Pt/C表现出更高的交换电 流密度, 归因于有序结构中 $\mathrm{Pd}$ 和 $\mathrm{Fe}$ 之间存在的强 相互作用以及 $\mathrm{PdFe}$ 核对 Pt壳产生的配体效应和应 变效应, 能减弱 $\mathrm{Pt}$ 壳对氢的吸附, 提升催化活性。 Innocente等 ${ }^{123}$ 研究表明 $\mathrm{PtSb}$ 和PtSn有序金属间化 合物在 $0.15 \mathrm{~mol} \cdot \mathrm{L}^{-1} \mathrm{HClO}_{4}$ 溶液中催化HOR时, 因 为 $\mathrm{Sb}$ 和 $\mathrm{Sn}$ 的加入能改变 $\mathrm{Pt}$ 表面吸附位的电子密 度, 从而改善对氢的吸附, 两者动力学电流密度 $i_{\mathrm{k}}$ 分别比Pt电极高2.1倍和1.3倍。Santos等 ${ }^{124}$ 研究了 三种金属间化合物 $\mathrm{Pt}_{3} \mathrm{Sn} 、 \mathrm{PtSn}$ 和 $\mathrm{PtSn}_{2}$ 的HOR, 发 现 $\mathrm{Pt}_{3} \mathrm{Sn}$ 和PtSn表现出与 $\mathrm{Pt}$ 相同的活性, 而 $\mathrm{PtSn}_{2}$ 没 有活性。HOR是由Pt的 $d$ 带与氢 $1 s$ 轨道的耦合决定 的。作者计算了三种金属间化合物的Pt- $d$ 带结构, 并与纯Pt的结构进行了比较, 发现三种金属间化 合物中 $\mathrm{Pt}$ 的 $d$ 带都被填满, 说明电子从 $\mathrm{Sn}$ 向 $\mathrm{Pt}$ 转移。 DFT计算发现 $\mathrm{PtSn}_{2}$ 的活化势垒高达 $0.65 \mathrm{eV}$, 远超 最佳活化势垒 $(0.3-0.5 \mathrm{eV})$, 故没有 HOR催化活性。

合金化能有效促进HOR活性的提升, 但电子 效应和双功能效应哪个才是影响HOR活性的关键 一直被争议。Bortoloti等 125 发现PtSn 金属间化合物 纳米晶在无 $\mathrm{CO}$ 覆盖和有 $\mathrm{CO}$ 覆盖下, 催化 $\mathrm{HOR}$ 活 性与商业 $\mathrm{Pt} / \mathrm{C}$ 相当, 且 $\mathrm{PtSn} / \mathrm{C}$ 不易吸附 $\mathrm{CO}$, 故 $\mathrm{CO}$ 的存在对HOR无抑制作用。X射线吸收光谱分析表 明, 由 $\mathrm{Sn}$ 向Pt转移电子是提升 $\mathrm{HOR}$ 活性和抗 $\mathrm{CO}$ 中 毒的关键。但 Wang 等 ${ }^{126}$ 制备了核壳结构的 $\mathrm{Pd}_{3} \mathrm{M} @ \mathrm{Pt} / \mathrm{C}(\mathrm{M}=\mathrm{Fe} 、 \mathrm{Co} 、 \mathrm{Cu})$ 催化剂, 通过电化 学检测HOR过程发现, 影响HOR催化活性的是低 价 $\mathrm{M}(\mathrm{OH})_{x}$ 物种对 $\mathrm{OH}^{*}$ 的较强吸附, 而不是因为表 
面应变和电子效应引起的HBE改变。

\subsection{2甲酸氧化反应(FAOR)}

FAOR催化剂的低活性和低稳定性抑制了直 接甲酸燃料电池的实际应用。甲酸氧化是一个双 电子反应, 反应机制有两条路径 ${ }^{127}$ 。(1)直接路径 (脱氢): $\mathrm{HCOOH} \rightarrow \mathrm{COOH}_{\mathrm{ads}} / \mathrm{HCOO}_{\mathrm{ads}}+\mathrm{H}^{+}+\mathrm{e} \rightarrow$ $\mathrm{CO}_{2}+2 \mathrm{H}^{+}+2 \mathrm{e}$; (2)间接路径(脱水): $\mathrm{HCOOH} \rightarrow$ $\mathrm{CO}_{\mathrm{ads}}+\mathrm{H}_{2} \mathrm{O} \rightarrow \mathrm{CO}_{2}+2 \mathrm{H}^{+}+2 \mathrm{e}$ 。对于多晶Pt催化 剂, 普遍认为主要是通过间接路径来催化甲酸氧 化进行, 但产生的中间体 $\mathrm{CO}_{\mathrm{ads}}$ 会吸附在催化剂活 性位点, 从而导致催化剂中毒。引入其他金属(如 $\mathrm{Sb}^{128} 、 \mathrm{~Pb}^{129}$ 和 $\mathrm{Bi}^{130}$ 等)对 $\mathrm{Pt} / \mathrm{Pd}$ 进行合金化, 可以 分散纳米晶表面的 $\mathrm{Pt} / \mathrm{Pd}$ 活性位点。这种表面不利 于 $\mathrm{CO}_{\mathrm{ads}}$ 的生成, 因此能有效阻止甲酸氧化的间接 反应途径。同时, $\mathrm{Pt} / \mathrm{Pd}$ 与引入的金属进行合金化 或改性时, $\mathrm{OH}^{*}$ 物种可以吸附在比 $\mathrm{Pt} / \mathrm{Pd}$ 电位更低 的元素上, 从而促进 $\mathrm{CO}_{\mathrm{ads}}$ 氧化, 提升材料的催化 活性 131 。

研究表明, 催化剂表面不连续排列的Pt原子可 以抑制FAOR的 “脱水” 途径, Abruña课题组 ${ }^{45,132,133}$ 合成了 $\mathrm{PtPb}$ 和 $\mathrm{PtBi}$ 金属间化合物纳米晶, 与商业的 $\mathrm{Pt}$ 和 $\mathrm{PtRu}$ 催化剂相比, $\mathrm{PtPb}$ 和PtBi纳米晶对甲酸和 甲醇的氧化表现出更高的起始电位和更大的电流 密度。作者还用傅里叶变换红外光谱(FTIR)研究 了所制备催化剂的电催化动力学, 证实了在 $\mathrm{PtPb}$ 和PtBi催化的FAOR中, 直接途径起主导作用。Sun 等 ${ }^{134}$ 制备了六方 $\mathrm{PtBi}$ 金属间化合物纳米片, 甲酸氧 化的 $\mathrm{MA}$ 高达 $9.06 \mathrm{~A} \cdot \mathrm{mg}^{-1}$, 原位红外(FTIR)分析表 明, $\mathrm{PtBi} / \mathrm{C}$ 催化剂上FAOR的间接脱水途径完全被 抑制。王得丽课题组 ${ }^{135}$ 通过浸渍还原法制备了有 序 $\mathrm{PtZn}$ 金属间化合物, $\mathrm{Zn}$ 元素的引入可以有效提 高催化剂的抗CO中毒能力, 在 $0.5 \mathrm{~V}(\mathrm{vs}$. RHE)下, $\mathrm{PtZn} / \mathrm{C}$ 的 MA约为商业 $\mathrm{Pt} / \mathrm{C}$ 的 $2-3$ 倍。后续在 $\mathrm{Pt}$ 晶格 中引入 $\mathrm{Ni}$ 和 $\mathrm{Co}$, 制备了 $\mathrm{PtCoNi}$ 三元金属间化合 物 ${ }^{136}$, 由于 $\mathrm{Pt} 、 \mathrm{Co} 、 \mathrm{Ni}$ 之间的强相互作用, 样品的 $\mathrm{MA}$ 是 $\mathrm{Pt} / \mathrm{C}$ 的2-3倍, 不仅表现出较高的FAOR峰电 流密度, 而且提高了抗CO中毒能力。Quan等 ${ }^{130}$ 合 成了 $\mathrm{PtSnBi}$ 金属间化合物纳米片以催化FAOR, 由 于这三种金属的协同作用, $\mathrm{Pt}_{45} \mathrm{Sn}_{25} \mathrm{Bi}_{30}$ 纳米片的 MA高达 $4394 \mathrm{~mA} \cdot \mathrm{mg}^{-1}$, 并在 4000 周循环后初始活 性仍保留 $78 \%$ 。DFT计算表明, PtSnBi金属间化合 物纳米片中的电子效应和应变效应能有效抑制 $\mathrm{CO}_{\mathrm{ads}}$ 的生成, 优化脱氢步骤。

目前很多Pd基催化剂被广泛用于甲酸氧化, 因为Pd基催化剂更倾向于 “脱氢” 途径, 故表现 出比 $\mathrm{Pt}$ 基催化剂更强的抗 $\mathrm{CO}$ 中毒能力 ${ }^{137}$ 。 $\mathrm{Lu}$ 等 ${ }^{138}$
制备了三维多孔PdSn金属间化合物, 由PdSn进行 甲酸氧化的 Tafel曲线中看到, $\mathrm{PdSn} / \mathrm{C}$ 和 $\mathrm{Pd} / \mathrm{C}$ 的 Tafel斜率很小, 而 Tafel斜率和 CO 覆盖率的大小成 正比, 说明在 $\mathrm{Pd}$ 基催化剂表面仅有很少 $\mathrm{CO}$ 覆盖, 甲酸氧化是通过脱氢途径进行的。王得丽课题组 42 制备了有序PdBi金属间化合物纳米晶, 通过隔离 $\mathrm{Pd}$ 原子来减少 $\mathrm{CO}_{\mathrm{ads}}$ 等吸附物种的形成。与 $\mathrm{Pd}$ 相 比, 有序PdBi的抗中毒能力增强, 在FAOR过程中 具有更优异的活性和稳定性。差分电化学质谱 (DEMS)和原位衰减全反射红外光谱(ATR-IR)表 明, 有序 $\mathrm{PdBi}$ 表面 $\mathrm{CO}_{\mathrm{ads}}$ 的生成被有效抑制。此外 还制备了表面富含 $\mathrm{Sn} / \mathrm{SnO}_{x}$ 的有序与无序 $\mathrm{Pd}-\mathrm{Sn}$ 纳 米晶 ${ }^{139}$, 发现影响FAOR催化活性的主要因素有两 个: (1) PdSn相对于Pd发生晶格扩张, 产生拉伸应 变抑制直接反应进行; (2)表面不连续的Pd位能抑 制脱水路径来减少 $\mathrm{CO}_{\mathrm{ads}}$ 等吸附物种生成, 促进直 接反应进行, 故 $\mathrm{PdSn}$ 催化剂活性的提升主要是因 为不连续Pd位点活性和抗毒性更高。Peter等 ${ }^{140}$ 制 备了花状 $\mathrm{Pd}_{3} \mathrm{~Pb}$ 纳米晶, 与商业 $\mathrm{Pd} / \mathrm{C}$ 相比, 在 0.5 $\mathrm{mol} \cdot \mathrm{L}^{-1} \mathrm{HClO}_{4}$ 电解液中, 甲酸氧化的 $\mathrm{MA}$ 和 $\mathrm{SA}$ 分 别为 $1.05 \mathrm{~A} \cdot \mathrm{mg}^{-1}$ 和 $6.83 \mathrm{~mA} \cdot \mathrm{cm}^{-2}$, 分别是 $\mathrm{Pd} / \mathrm{C}$ 的 2.4 倍和 2.5 倍。Kang 等 ${ }^{141}$ 合成了金属间化合物 $\mathrm{Pt}_{3} \mathrm{~Pb}$ 纳 米晶。 $\mathrm{Pt}_{3} \mathrm{~Pb} @ \mathrm{Pt}$ 核壳结构的生成进一步提高了催 化剂的活性, 这可能是由于脱氢势垒的不断降低、 反应物分子的强吸附, 最重要的是抑制了脱水生 成甲酸路径, 避免了甲酸盐中间体因占据活性位 点而抑制反应进行。

引入具有高比表面积的载体也可以有效提升 甲酸氧化的催化性能。Lee等64制备了以有序大孔 介孔碳-二氧化硅(OMCS)复合材料为载体的有序 金属间化合物 $\mathrm{PtPb}$ 催化剂, 呈二维六角形孔结构, 其中 $\mathrm{PtPb}$ 高度分散。与商业 $\mathrm{Pt} / \mathrm{C}$ 相比, $\mathrm{PtPb}$ 的质量 活性提高了 10 倍以上, FAOR的起始电位显著降 低, 并且具有良好的抗 CO中毒性能, 表现出极优 异的稳定性。将其用于DFAFC, 其最大功率密度 远高于商业 $\mathrm{Pt} / \mathrm{C}\left(236.08 \mathrm{~mW} \cdot \mathrm{mg}^{-1}\right.$ vs. 120.65 $\left.\mathrm{mW} \cdot \mathrm{mg}^{-1}\right)$ 。后来, 同组通过在介孔碳的孔壁里面 加入硅酸铝试剂生成了 $\mathrm{PtPb}-\mathrm{OMCA}{ }^{142}$, 硅酸铝反 应生成的氧化铝会与铂族金属有很强的相互作 用。即使金属负载量很高, 金属间化合物纳米晶在 介孔中也有很好的分散。合成的材料平均粒径为 $4.4 \mathrm{~nm}$, 由于 $\mathrm{PtPb}$ 金属间化合物的形成、 $\mathrm{Pb}$ 优异的 抗 $\mathrm{CO}$ 中毒能力以及 $\mathrm{PtPb}$ 与载体之间的强相互作 用, 材料的 $\mathrm{MA}$ 为 $2.66 \mathrm{~A} \cdot \mathrm{mg}^{-1}$, 相对于 $\mathrm{Pt} / \mathrm{C}$ 提高了 10 倍。Tang等66通过采用碳载氧凝胶衍生策略合成 了有序 $\mathrm{Pd}_{3} \mathrm{Fe}$ 金属间化合物, 催化FAOR的MA为 
696.4 A. $\mathrm{g}^{-1}$, 分别是无序 $\mathrm{Pd}_{3} \mathrm{Fe} / \mathrm{C}$ 和 $\mathrm{Pd} / \mathrm{C}$ 的 1.41 倍和 1.91倍。Xia等 ${ }^{143}$ 制备了以氧化石墨烯为载体的 N$\mathrm{PtTe}$ 催化剂, $\mathrm{Te}$ 的引入有利于 $\mathrm{OH}^{*}$ 的吸附, 从而促 使 $\mathrm{Pt}$ 将 $\mathrm{CO}_{\mathrm{ads}}$ 转化为 $\mathrm{CO}_{2}$, 提高催化剂的抗 $\mathrm{CO}$ 中毒 能力。

\subsection{3甲醇氧化反应 (MOR)}

$\mathrm{MOR}$ 生成 $\mathrm{CO}_{2}$ 的过程是 6 电子转移过程, 其中 可能会生成甲酸中间体, Casado-Rivera等 ${ }^{45}$ 研究发 现, 因为有相似的中间产物, 每一种具有MOR活 性的金属间化合物在FAOR中也有活性。相对于 $\mathrm{FAOR}$, 为达到甲醇的完全氧化, 吸附 $\mathrm{OH}^{*}$ 促进 $\mathrm{CO}_{\mathrm{ads}}$ 生成 $\mathrm{CO}_{2}$ 更加重要。

王得丽课题组 ${ }^{144}$ 通过浸渍还原法以及后续自 发置换，用 $\mathrm{Cu}$ 取代PtFe金属间化合物中的 $\mathrm{Fe}$ 原子 制备了三元有序金属间化合物纳米晶 $\mathrm{PtFeCu}$ 。虽 然 $\mathrm{Cu}$ 的加入导致晶格收缩, $\mathrm{PtFeCu}$ 相对于 $\mathrm{PtFe}$ 对 $\mathrm{CO}_{\text {ads }}$ 物种产生了较强吸附, 降低了MOR催化活 性, 但是 $\mathrm{Cu}$ 的存在能促使纳米晶在较低的退火温 度下从无序的fcc相向有序的fct相转变。另外相对 惰性的 $\mathrm{Cu}$ 取代 $\mathrm{Fe}$ 也能有效提升材料在酸性电解液 中的稳定性。对比发现, 相对于 $\mathrm{PtFe}$ 和 $\mathrm{PtFe}_{0.5} \mathrm{Cu}_{0.5}$, $\mathrm{PtFe}_{0.7} \mathrm{Cu}_{0.3}$ 表现出最高的活性与稳定性(图11a)。为 了促进对MOR机理的研究, 后续通过DEMS观察 了 $\mathrm{PtFeCu}$ 三元有序金属间化合物催化MOR反应的 中间体 ${ }^{145}$, 发现 $\mathrm{PtFe}_{0.7} \mathrm{Cu}_{0.3} / \mathrm{C}$ 具有最高的 $\mathrm{CO}_{2}$ 生成 效率, 而 $\mathrm{PtFe}_{0.5} \mathrm{Cu}_{0.5} / \mathrm{C}$ 产生甲酸甲酯和甲酸的比例 最大。不同的选择性归因于 $\mathrm{Fe}$ 和 $\mathrm{Cu}$ 原子的掺入引 起晶格压缩应变的不同。随着晶格收缩增加, 应变 的 $\mathrm{Pt}$ 晶格能催化甲醇稳定生成甲酸甲酯或甲酸; 但适当减小晶格收缩量可以削弱 $\mathrm{CO}_{\mathrm{ads}}$ 结合能, 促 进 $\mathrm{CO}_{\mathrm{ads}}$ 氧化为 $\mathrm{CO}_{2}$; 如果晶格收缩过大, $\mathrm{CO}_{\mathrm{ads}}$ 不 易吸附到催化剂表面, 则会阻碍 $\mathrm{CO}_{\mathrm{ads}}$ 生成 $\mathrm{CO}_{2}$ (图 11b-d)。

Zheng等 ${ }^{146}$ 制备了凹面立方 $\mathrm{Pt}_{3} \mathrm{Zn}$ 金属间化合 物纳米晶, 具有优异的抗 $\mathrm{CO}$ 中毒能力, 对MOR和 FAOR表现出优异的电催化活性。Huang 等 ${ }^{80}$ 在多 壁碳纳米管(MWNT)上合成了有序金属间化合物 $\mathrm{PtZn}$ 纳米晶, 粒径为 $3.2 \pm 0.4 \mathrm{~nm}$, 在 $0.5 \mathrm{~mol} \cdot \mathrm{L}^{-1}$ $\mathrm{H}_{2} \mathrm{SO}_{4}$ 和 $0.1 \mathrm{~mol} \cdot \mathrm{L}^{-1} \mathrm{KOH}$, 对 MOR均表现出较 好的稳定性和较高的活性。通过DFT计算(图11e), 将PtZn(111)、PtZn(211)和 $\mathrm{Pt}_{24} \mathrm{Zn}_{24}$ 簇来分别表示平 台位置、边缘位置和拐角位置, 得知反应路径遵循 能量趋势: $\mathrm{Pt}_{24} \mathrm{Zn}_{24}<\mathrm{PtZn}(211)<\mathrm{PtZn}(111)$, 说明 小粒径催化剂的催化性能优于大粒径的催化剂。 另外, 由于 $\mathrm{Zn}$ 原子可以稳定 $\mathrm{OH}^{*}$ 中间体, $\mathrm{PtZn}$ 纳米 晶在MOR反应中会经历 “非 $\mathrm{CO}$ ” 途径, 生成 $\mathrm{CH}_{3} \mathrm{O}^{*}$

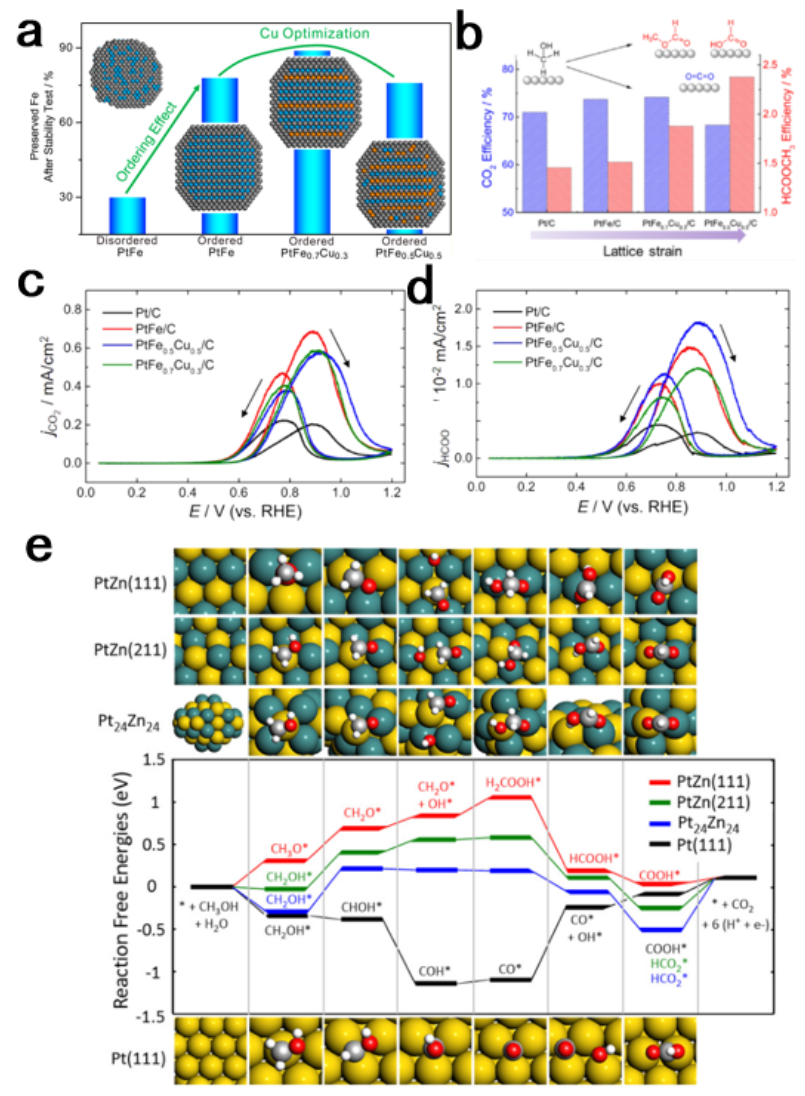

图11 (a)四种材料稳定性测试后 Fe的保留量; (b)分别催化生成 $\mathrm{CO}_{2}$ 和甲酸甲酯的效率; (c) $\mathrm{CO}_{2}$ 电流 密度-电压曲线; (d)甲酸甲酯电流密度-电压曲线 ${ }^{144}$;

(e) PtZn(111)、阶梯PtZn(211)、Pt ${ }_{24} Z_{24}$ 簇和 $\operatorname{Pt}(111)$ 对MOR的反应机理 ${ }^{80}$

Fig.11 (a) Preserved Fe after stability tests for four materials; (b) the conversion efficiency of $\mathrm{CO}_{2}$ and methyl formate respectively; cyclic voltammograms; (c) $\mathrm{CO}_{2}$ partial current density; (d) methyl formate partial current density ${ }^{144}$; (e) the reaction mec hanism of MOR on PtZn(111), stepped PtZn(211), $\mathrm{Pt}_{24} \mathrm{Zn}_{24}$ cluster and Pt(111) ${ }^{80}$.

Adapted from American Chemical Society Publisher.

或 $\mathrm{CH}_{2} \mathrm{OH}^{*}$ 中间体。而 $\mathrm{Pt}$ 体系由于会形成高度稳定 的 $\mathrm{COH}^{*}$ 和 $\mathrm{CO}^{*}$ 中间体, 会导致催化剂失活。

在催化剂表面的应变效应也广泛用来控制和 优化材料的MOR电催化性能。 $\mathrm{Li}$ 等 ${ }^{147}$ 制备了一种 具有 2-3 个 $\mathrm{Pt}$ 原子层的金属间化合物 $\mathrm{Pt}_{3} \mathrm{Ga}(\mathrm{AL}-$ $\left.\mathrm{Pt} / \mathrm{Pt}_{3} \mathrm{Ga}\right)$ 。HAADF-STEM表征表明, AL-Pt/Pt ${ }_{3} \mathrm{Ga}$ 在 [001]方向上有 $3.2 \%$ 的拉伸应变, 而在 [100]和 [010]方向上的应变可以忽略不计。将其用于 $\mathrm{MOR}$, 具有拉伸应变的 $\mathrm{AL}-\mathrm{Pt} / \mathrm{Pt}_{3} \mathrm{Ga}$ 电催化剂的 $\mathrm{SA}$ 和MA分别为 $7.195 \mathrm{~mA} \cdot \mathrm{cm}^{-2}$ 和 $1.094 \mathrm{~A} \cdot \mathrm{mg}^{-1}$, 远高 于无应变催化剂和商业 $\mathrm{Pt} / \mathrm{C}$ 催化剂。DFT计算表 
明, 因为 $\mathrm{OH}^{*}$ 在拉伸的 $\mathrm{AL}-\mathrm{Pt} / \mathrm{Pt}_{3} \mathrm{Ga}$ 表面结合较强, 有利于 $\mathrm{CO}$ 的去除, 故拉伸应变的表面比无应变的 表面更有利于MOR。Li等 ${ }^{148}$ 用一锅法制备了由金 属间化合物 PtBi 核和超薄 Pt壳组成的六方 $\mathrm{PtBi} / \mathrm{Pt}$ 核/壳纳米结构催化剂。在 $0.1 \mathrm{~mol} \cdot \mathrm{L}^{-1} \mathrm{NaOH}$ 溶液 中, 进行 MOR和EOR测试, MA分别为 4820 和 5950 $\mathrm{mA} \cdot \mathrm{mg}^{-1}$, 分别是商业 $\mathrm{Pt} / \mathrm{C}$ 催化剂的 6.15 和 8.63 倍, 并且具有很好的稳定性。通过 X射线光电子能谱 (XPS)发现, Pt和Bi在纳米片中存在电子效应, 电 子从 $\mathrm{Bi}$ 转移到 $\mathrm{Pt}$, 填充 $\mathrm{Pt}$ 的 $5 d$ 轨道, 使 $\mathrm{Pt}$ 的 $d$ 带中心 下降, 吸附在催化剂表面的中间体 $\mathrm{CO}_{\mathrm{ads}}$ 等含氧物 种减少。另外由于 $\mathrm{Pt}$ 与 $\mathrm{Bi}$ 之间存在晶格错配, 使 $\mathrm{Pt}$ 壳产生应变效应, 进一步提升催化性能。

$A b e$ 等 ${ }^{27}$ 经测试得到, 与 Pt、PtRu相比, 有序

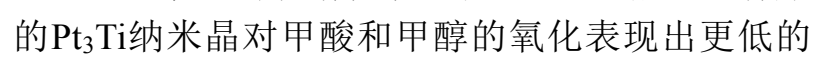
起始电位和更高的氧化电流密度。结果表明, 有序 $\mathrm{Pt}_{3}$ Ti纳米晶活性较高的原因是 $\mathrm{CO}_{\mathrm{ads}}$ 在材料表面吸 附强度较弱, 促进了MOR的直接途径。Kang等 149 制备了立方和球形PtMn纳米立方体 $(\mathrm{NCs})$, 对于甲 酸氧化, 立方和球形PtMn NCs的活性均低于 $\mathrm{Pt} / \mathrm{C}$, 但立方PtMn NCs的活性高于球形PtMn NCs。然 而, 对于甲醇氧化, 立方体PtMn NCs的活性优于 $\mathrm{Pt} / \mathrm{C}$, 而球形PtMn NCs的甲醇氧化活性与 $\mathrm{Pt} / \mathrm{C}$ 相 当。这些结果表明, PtMn的(100)面比(111)面具有 更高的甲酸和甲醇氧化活性。Huang等99制备了六 方核壳结构的 $\mathrm{PtPb} / \mathrm{Pt}$ 纳米板, 对甲醇氧化反应 (MOR) 和乙醇氧化反应 $(\mathrm{EOR})$ 等阳极燃料电池反 应也表现出优异的电催化活性和稳定性, DFT计 算表明, 活性增强与 $\mathrm{C}-\mathrm{H}$ 和 $\mathrm{O}-\mathrm{H}$ 键的活化以及改 善了 $\mathrm{OH}^{*}$ 和 $\mathrm{CO}_{\mathrm{ads}}$ 的吸附能有关。

\subsection{4 乙醇氧化反应 $(E O R)$}

乙醇完全氧化是发生 12 电子转移生成 $\mathrm{CO}_{2}$ : $\mathrm{CH}_{3} \mathrm{CH}_{2} \mathrm{OH}+3 \mathrm{H}_{2} \mathrm{O} \rightleftharpoons 2 \mathrm{CO}_{2}+12 \mathrm{H}^{+}+12 \mathrm{e}$; 部分氧 化是发生 4 电子转移生成乙酸 ${ }^{150}: \mathrm{CH}_{3} \mathrm{CH}_{2} \mathrm{OH}+$ $\mathrm{H}_{2} \mathrm{O} \rightleftharpoons \mathrm{CH}_{3} \mathrm{COOH}+4 \mathrm{H}^{+}+4 \mathrm{e}$; 发生 2 电子转移生成 乙醛: $\mathrm{CH}_{3} \mathrm{CH}_{2} \mathrm{OH} \rightleftharpoons \mathrm{CH}_{3} \mathrm{CHO}+2 \mathrm{H}^{+}+2 \mathrm{e}$ 。乙醇发 生完全氧化的路径中因为 $\mathrm{C}-\mathrm{C}$ 键断裂需要很高的 解离能(约 $350 \mathrm{~kJ} \cdot \mathrm{mol}^{-1}$ ), 并且不完全断裂会生成大 量 $\mathrm{CO}$ 中间体, 毒化催化剂活性位点。为使 $\mathrm{C}-\mathrm{C}$ 键 断裂, 需要在Pt或 $P d$ 中入更具有正电性和更亲 氧的元素吸附溶液中的 $\mathrm{OH}^{*}$, 氧化相邻 $\mathrm{Pt} / \mathrm{Pd}$ 上的 反应中间体, 促进 $\mathrm{C}-\mathrm{O}$ 键生成, 发生乙醇的完全 氧化。

Abe等 ${ }^{151}$ 通过共还原法合成 $\mathrm{TaPt}_{3}$ 金属间化合 物纳米晶, 进行 $\mathrm{EOR}$ 的峰电流密度是 $\mathrm{Pt}$ 纳米粒子 的3倍, 起始电位是 $0.27 \mathrm{~V}$, 相对于 Pt纳米粒子低
$0.17 \mathrm{~V}$ 。较高的峰电流密度和较低的氧化起始电位 归因于 $\mathrm{Ta}$ 与水反应生成 $\mathrm{Ta}-\mathrm{OH}$, 进一步氧化吸附在 $\mathrm{Pt}$ 原子上的反应中间体。原位FTIR分析表明, $\mathrm{TaPt}_{3}$ 纳米晶能在低电位下有效催化乙醇中的 $\mathrm{C}-\mathrm{C}$ 裂 解, 促进乙醇向 $\mathrm{CO}_{2}$ 的完全转化。在 $0.5 \mathrm{~mol} \cdot \mathrm{L}^{-1}$ $\mathrm{H}_{2} \mathrm{SO}_{4}$ 溶液中测试材料的循环稳定性, 发现在 10000 周之后ECSA仍保留初始的 $85 \%$ 。良好的循 环稳定性归因于金属间化合物相的生成。Peter等 152 通过改变反应时间合成了不同尺寸的 $\mathrm{Pd}_{2} \mathrm{Ge}$ 金属 间化合物纳米晶, 通过XRD和XPS发现反应 $24 \mathrm{~h}$ 得 到的产物 $\mathrm{Pd}_{2} \mathrm{Ge}-24$ 中存在 $\mathrm{Ge}$ 的空位, 该催化剂在 $0.1 \mathrm{~mol} \cdot \mathrm{L}^{-1} \mathrm{KOH}$ 中的归一化电流密度分别为 4.1 $\mathrm{mA} \cdot \mathrm{cm}^{-2}$, 是商业 $\mathrm{Pd} / \mathrm{C}$ 的 2.2 倍, 优于反应 $36 \mathrm{~h}$ 得到 的没有空位的样品, 说明缺陷可以增强反应的催 化活性。Wang 等 ${ }^{153}$ 制备了有序 $\mathrm{Pd}_{2} \mathrm{Sn}$ 纳米晶, 与无 序 $\mathrm{Pd}_{2} \mathrm{Sn}$ 及 $\mathrm{Pd} / \mathrm{C}$ 相比, 因为 $\mathrm{Sn}$ 改变了 $\mathrm{Pt}$ 的电子结 构, 改变了中间体在催化剂上的吸附能, 在EOR中 具有优异的催化活性。Nguyen等 ${ }^{154-156}$ 研究了在碱 性介质中Pd电极上的EOR机理, 发现 $\mathrm{C}_{2} \mathrm{H}_{5} \mathrm{OH}$ 连续 脱氢生成 $\mathrm{CH}_{3} \mathrm{CHO}_{\mathrm{ads}}$ 中间体, 该中间体会吸附在 $\mathrm{Pd}$ 表面, 阻碍后续 $\mathrm{C}_{2} \mathrm{H}_{5} \mathrm{OH}$ 氧化的进行, 这步氧化反 应是EOR的决速步。Guo等 ${ }^{157}$ 制备了 $\mathrm{PdCuCo}$ 有序 金属间化合物纳米晶, 对EOR的MA分别是商用 $\mathrm{Pt} / \mathrm{C}$ 和 $\mathrm{Pd} / \mathrm{C}$ 催化剂的 12.9 倍和 17.5 倍。DFT计算表 明, 由于较小的 $\mathrm{Cu} 、 \mathrm{Co}$ 具有较小的原子尺寸, 配 体效应和 $\mathrm{Pd}$ 表面的压缩应变使得 $\mathrm{PdCuCo}$ 纳米晶 的ORR活性提高。Atanassov等 158 通过牺牲 $\mathrm{SiO}_{2}$ 载 体和高温还原相结合的方法合成了系列高活性 Pd-In催化剂 $\left(\mathrm{Pd}_{3} \mathrm{In}, \mathrm{PdIn}\right.$ 和PdIn 3 )。结果表明, 在 所有Pd-In材料中, In对EOR均有促进作用, 催化活 性与反应条件下的部分去合金化有关。

具有高比表面积的纳米片和纳米线由于具有 大量活性位点, 在EOR中也有极优异的性能。Shi 等 159 制备了有序 $\mathrm{Pd}_{3} \mathrm{~Pb}$ 纳米线, $\mathrm{Pb}$ 的引入可以优化 $\mathrm{Pt}$ 的电子结构, 降低对中间产物的吸附能, 超细纳 米线的表面为催化反应进行提供了大量活性位 点。Huang等 160 制备了一维超薄有序 $\mathrm{Pt}_{3} \mathrm{Sn}$ 纳米纤 维, 用于催化EOR。一维结构可以增大其电化学活 性面积, 在Pt中引入 $\mathrm{Sn}$, 可以促进电解液中含氧物 种的吸附, 有效减轻反应中间体的结合强度, 促进 中间体的电氧化, 提升催化EOR的活性与稳定性。 Zhang 等 161 制备了有序 fct-PdZn 纳米片, 在 1.0 $\mathrm{mol} \cdot \mathrm{L}^{-1} \mathrm{NaOH}$ 溶液中进行电化学测试, $\mathrm{MA}$ 为 2.73 $\mathrm{A} \cdot \mathrm{mg}^{-1}$, 分别是纯 $\mathrm{Pd}$ 纳米片 $\left(1.57 \mathrm{~A} \cdot \mathrm{mg}^{-1}\right)$ 和 $\mathrm{Pd}$ 黑 $\left(0.92 \mathrm{~A} \cdot \mathrm{mg}^{-1}\right)$ 的1.74倍和 2.97 倍。XPS表明, 与纯Pd 纳米片相比, $\mathrm{PdZn}$ 纳米片中 $\mathrm{Pd}^{0}$ 的峰发生了负移, 
说明 $\mathrm{Pd}$ 与 $\mathrm{Zn}$ 之间发生了电子转移。另外, 循环伏 安曲线中, $\mathrm{PdZn}$ 纳米片显示出明显增强的 $\mathrm{PdO}$ 还 原峰, 这与催化剂表面的 $\mathrm{OH}^{-}$吸附成正比, 表明 $\mathrm{PdZn}$ 的电化学比表面积较大。Pd电子结构的改变 以及电化学活性面积的增加有效提升了 $\mathrm{PdZn}$ 纳米 片的催化活性。

\section{5 总结与展望}

本文基于课题组多年来在金属间化合物方面 的研究, 综述了 Pt/Pd基金属间化合物的结构特征、 优点以及近些年的研究进展, 重点阐述了金属间 化合物的制备方法(热退火法和直接液相合成法) 以及其在燃料电池电催化中的应用。热退火法是 制备金属间化合物最通用的方法, 可以精确控制 纳米晶的组成及原子有序性, 但只能生成热力学 稳定的球形纳米晶。纳米晶在高温退火过程中极 易发生团聚, 通过包覆或者使用载体等可以有效 抑制, 但包覆层会阻碍原子的互扩散, 可能只能得 到部分有序的纳米晶。直接液相合成法可以在较 低温度下使用温和的还原剂来减慢成核以及生长 过程中的动力学, 可用于制备特定形貌的金属间 化合物纳米晶, 但是成核的过程以及形状演变的 机制目前仍不明确, 材料合成的可重复性也有待 提高, 需要对反应动力学进行更多的研究以精确 控制纳米晶的成核及生长过程, 以实现在低温下 高效大规模生产制备颗粒分散、粒径均匀、形貌可 控的金属间化合物。

另外，不同原子之间的相互作用(电子效应、 应变效应、双功能机理等)非常复杂, 我们还未能 完全了解其本质, 对催化剂催化机理认识也仍不 深入。目前对于金属间化合物催化剂活性增强的 主要原因一直没有明确的答案。 $\mathrm{Pt} / \mathrm{Pd}$ 基金属间化 合物的发展还有很多提升的空间: (1)为了更好地 控制金属间化合物纳米晶合成过程中的形状，需 要在反应动力学和热力学中进行更深层次的探索 和研究, 深入了解纳米晶的形成机理, 以期得到具 有更多活性位点和更高催化活性的催化剂。(2)在 讨论 $\mathrm{Pt} / \mathrm{Pd}$ 基催化剂的催化性能时, 应测试其在 MEA体系中的活性与稳定性, 而不能只局限于 $\mathrm{RDE}$ 测试。由于在RDE测试中, 高速旋转的电极可 以很大程度上消除 $\mathrm{O}_{2}$ 在电解液中的传质阻力, 很 多催化剂有较优异的ORR性能。但在实际MEA工 作体系中, $\mathrm{O}_{2}$ 的传质阻力不可忽略, 并且工作温度 远高于RDE测试, 导致在RDE测试中具有优异性 能的催化剂并不能在MEA测试中达到同样高的性 能。(3)通过原位表征技术, 如原位红外光谱
(FTIRS)、透射电镜(TEM)、X射线衍射(XRD)、同 步辐射(XAFS)等监测反应过程中催化剂表面及反 应物种的变化, 推进反应机理的研究。(4)通过理 论计算指导合成催化剂, 并研究催化剂界面上的 动力学过程以进一步指导实验。

\section{References}

(1) Dunn, B.; Kamath, H.; Tarascon, J. M. Science 2011, 334, 928. doi: $10.1126 /$ science. 1212741

(2) Bing, Y.; Liu, H.; Zhang, L.; Ghosh, D.; Zhang, J. Chem. Soc. Rev. 2010, 39, 2184. doi: 10.1039/b912552c

(3) Rößner, L.; Armbrüster, M. ACS Catal. 2019, 9, 2018. doi: 10.1021/acscatal.8b04566

(4) Luo, M. C.; Sun, Y. J.; Qin, Y. N.; Yang, Y.; Wu, D.; Guo, S. J. Acta Phys. -Chim. Sin. 2018, 34, 361. [骆明川, 孙英俊, 秦英楠, 杨勇, 吴冬, 郭少军. 物理化学学报, 2018, 34, 361.] doi: 10.3866/PKU.WHXB201708312

(5) Ma, Z.; Cano, Z. P.; Yu, A.; Chen, Z.; Jiang, G.; Fu, X.; Yang, L.; Wu, T.; Bai, Z.; Lu, J. Angew. Chem. Int. Ed. 2020, 59, 18334. doi: 10.1002/anie.202003654

(6) Wang, X. X.; Sokolowski, J.; Liu, H.; Wu, G. Chin. J. Catal. 2020, 41, 739. doi: 10.1016/s1872-2067(19)63407-8

(7) Bashyam, R.; Zelenay, P. Nature 2006, 443, 63. doi: $10.1038 /$ nature 05118

(8) Shao, M.; Chang, Q.; Dodelet, J. P.; Chenitz, R. Chem. Rev. 2016, 116, 3594. doi: 10.1021/acs.chemrev.5b00462

(9) Xia, B. Y.; Wu, H. B.; Wang, X.; Lou, X. W. J. Am. Chem. Soc. 2012, 134, 13934. doi: $10.1021 / \mathrm{ja} 3051662$

(10) Hodnik, N.; Jeyabharathi, C.; Meier, J. C.; Kostka, A.; Phani, K. L.; Recnik, A.; Bele, M.; Hocevar, S.; Gaberscek, M.; Mayrhofer, K. J. Phys. Chem. Chem. Phys. 2014, 16, 13610. doi: 10.1039/c4cp00585f

(11) Zhang, Z.; Luo, Z.; Chen, B.; Wei, C.; Zhao, J.; Chen, J.; Zhang, X.; Lai, Z.; Fan, Z.; Tan, C.; et al. Adv. Mater. 2016, 28, 8712. doi: 10.1002/adma.201603075

(12) Sun, S.; Murray, C. B.; Weller, D.; Folks, L.; Moser, A. Science 2000. doi: $10.1002 / \operatorname{chin} .200027244$

(13) Liu, Z.; Jackson, G. S.; Eichhorn, B. W. Energy Environ. Sci. 2011, 4, 1900. doi: $10.1039 / \mathrm{c} 1$ ee $01125 \mathrm{a}$

(14) Chung, D. Y.; Jun, S. W.; Yoon, G.; Kwon, S. G.; Shin, D. Y.; Seo, P.; Yoo, J. M.; Shin, H.; Chung, Y. H.; Kim, H.; et al. J. Am. Chem. Soc. 2015, 137, 15478. doi: 10.1021/jacs.5b09653

(15) Leonard, B. M.; Zhou, Q.; Wu, D.; DiSalvo, F. J. Chem. Mater. 2011, 23, 1136. doi: 10.1021/cm1024876

(16) Wang, Y.; Zou, L.; Huang, Q.; Zou, Z.; Yang, H. Int. J. Hydrogen Energy 2017, 42, 26695. doi: 10.1016/j.ijhydene.2017.09.008 
(17) Wang, D.; Xin, H. L.; Hovden, R.; Wang, H.; Yu, Y.; Muller, D. A.; DiSalvo, F. J.; Abruna, H. D. Nat. Mater. 2013, 12, 81.

doi: $10.1038 /$ nmat 3458

(18) Stamenkovic, V. R.; Mun, B. S.; Arenz, M.; Mayrhofer, K. J.; Lucas, C. A.; Wang, G.; Ross, P. N.; Markovic, N. M. Nat. Mater. 2007, 6, 241. doi: $10.1038 /$ nmat 1840

(19) Cui, C.; Gan, L.; Heggen, M.; Rudi, S.; Strasser, P. Nat. Mater. 2013, 12, 765. doi: $10.1038 /$ nmat 3668

(20) Zhang, X.; Lu, G. J. Phys. Chem. Lett. 2014, 5, 292. doi: $10.1021 /$ jz4024699

(21) Bligaard, T.; Nørskov, J. K. Electrochim. Acta 2007, 52, 5512. doi: 10.1016/j.electacta.2007.02.041

(22) Mavrikakis, M.; Hammer, B.; Nørskov, J. Phys. Rev. Lett. 1998, 81, 2819. doi: 10.1103/PhysRevLett.81.2819

(23) Karamad, M.; Tripkovic, V.; Rossmeisl, J. ACS Catal. 2014, 4, 2268. doi: $10.1021 / \mathrm{cs} 500328 \mathrm{c}$

(24) Wang, K.; Gasteiger, H. A.; Markovic, N. M. Electrochim. Acta 1996, 41, 2587. doi: 10.1016/0013-4686(96)00079-5

(25) Jaksic, M. M.; Botton, G. A.; Papakonstantinou, G. D.; Nan, F.; Jaksic, J. M. J. Phys. Chem. C 2014, 118, 8723. doi: $10.1021 / \mathrm{jp} 412292 \mathrm{w}$

(26) Jaksic, J. M.; Nan, F.; Papakonstantinou, G. D.; Botton, G. A.; Jaksic, M. M. J. Phys. Chem. C 2015, 119, 11267. doi: 10.1021/jp510234f

(27) Abe, H.; Matsumoto, F.; Alden, L. R. J. Am. Chem. Soc. 2008, 130, 5452. doi: 10.1021/ja075061c

(28) DeSario, D. Y.; DiSalvo, F. J. Chem. Mater. 2014, 26, 2750. doi: $10.1021 / \mathrm{cm} 5007197$

(29) Wang, D.; Yu, Y.; Xin, H. L.; Hovden, R.; Ercius, P.; Mundy, J. A.; Chen, H.; Richard, J. H.; Muller, D. A.; DiSalvo, F. J.; Abruna, H. D. Nano Lett. 2012, 12, 5230. doi: 10.1021/n1302404g

(30) Liu, S.; Xiao, W.; Wang, J.; Zhu, J.; Wu, Z.; Xin, H.; Wang, D. Nano Energy 2016, 27, 475. doi: 10.1016/j.nanoen.2016.07.038

(31) Xiao, W.; Cordeiro, M. A. L.; Gao, G.; Zheng, A.; Wang, J.; Lei, W.; Gong, M.; Lin, R.; Stavitski, E.; Xin, H. L.; Wang, D. Nano Energy 2018, 50, 70. doi: 10.1016/j.nanoen.2018.05.032

(32) Galeano, C.; Meier, J. C.; Peinecke, V.; Bongard, H.; Katsounaros, I.; Topalov, A. A.; Lu, A.; Mayrhofer, K. J.; Schuth, F. J. Am. Chem. Soc. 2012, 134, 20457. doi: 10.1021/ja308570c

(33) Iihama, S.; Furukawa, S.; Komatsu, T. ACS Catal. 2015, 6, 742. doi: $10.1021 /$ acscatal.5b02464

(34) Najafishirtari, S.; Brescia, R.; Guardia, P.; Marras, S.; Manna, L.; Colombo, M. ACS Catal. 2015, 5, 2154. doi: 10.1021/cs501923x

(35) Kim J.; Lee Y.; Sun S. J. Am. Chem. Soc. 2010, 132, 4996. doi: $10.1021 /$ ja1009629

(36) Zou, L.; Li, J.; Yuan, T.; Zhou, Y.; Li, X.; Yang, H. Nanoscale 2014, 6, 10686. doi: 10.1039/c4nr02799j
(37) Cui, Y.; Wu, Y.; Wang, Z.; Yao, X.; Wei, Y.; Kang, Y.; Du, H.; Li, J.; Gan, L. J. Electrochem. Soc. 2020, 167, 064520. doi: 10.1149/1945-7111/ab8407

(38) Hu, Y.; Lu, Y.; Zhao, X.; Shen, T.; Zhao, T.; Gong, M.; Chen, K.; Lai, C.; Zhang, J.; Xin, H. L.; Wang, D. Nano Res. 2020, 13, 2365. doi: $10.1007 / \mathrm{s} 12274-020-2856-\mathrm{Z}$

(39) Yang, Y.; Chen, G.; Zeng, R.; Villarino, A. M.; DiSalvo, F. J.; van Dover, R. B.; Abruna, H. D. J. Am. Chem. Soc. 2020, 142, 3980. doi: $10.1021 /$ jacs. 9 b13400

(40) Shao, M. J. Power Sources 2011, 196, 2433. doi: 10.1016/j.jpowsour.2010.10.093

(41) Xiao, W.; Lei, W.; Wang, J.; Gao, G.; Zhao, T.; Cordeiro, M. A. L.; Lin, R.; Gong, M.; Guo, X.; Stavitski, E.; et al. J. Mater. Chem. A 2018, 6, 11346. doi: 10.1039/c8ta03250e

(42) Shen, T.; Chen, S.; Zeng, R.; Gong, M.; Zhao, T.; Lu, Y.; Liu, X.; Xiao, D.; Yang, Y.; Hu, J.; et al. ACS Catal. 2020, 10, 9977. doi: 10.1021/acscatal.0c01537

(43) Meku, E.; Du, C.; Sun, Y.; Du, L.; Wang, Y.; Yin, G. J. Electrochem. Soc. 2015, 163, F132. doi: 10.1149/2.0031603jes

(44) Takao, G.; Noh, S. H.; Fuma, A.; Toyokazu, T.; Byungchan, H.; Takeo, O. J. Mater. Chem. A 2018, 6, 14828. doi: 10.1039/C8TA03233E

(45) Casado-Rivera, E.; Volpe, D. J.; Alden, L.; Lind, C.; Downie, C.; Vazquez-Alvarez, T. J. Am. Chem. Soc. 2004, 126, 4043. doi: $10.1021 / \mathrm{ja} 038497 \mathrm{a}$

(46) Wang, D.; Yu, Y.; Zhu, J.; Liu, S.; Muller, D. A.; Abruna, H. D. Nano Lett. 2015, 15, 1343. doi: 10.1021/n1504597j

(47) Gong, M.; Zhu, J.; Liu, M.; Liu, P.; Deng, Z.; Shen, T.; Zhao, T.; Lin, R.; Lu, Y.; Yang, S.; et al. Nanoscale 2019, 11, 20301. doi: $10.1039 / \mathrm{c} 9 \mathrm{nr} 04975 \mathrm{~d}$

(48) Li, J.; Sun, S. Acc. Chem. Res. 2019, 52, 2015. doi: 10.1021/acs.accounts.9b00172

(49) Koh, S.; Toney, M. F.; Strasser, P. Electrochim. Acta 2007, 52, 2765. doi: 10.1016/j.electacta.2006.08.039

(50) Liu, Z.; Jackson, G. S.; Eichhorn, B. W. Angew. Chem. Int. Ed. 2010, 49, 3173. doi: 10.1002/anie.200907019

(51) Ji, X.; Lee, K. T.; Holden, R.; Zhang, L.; Zhang, J.; Botton, G. A.; Couillard, M.; Nazar, L. F. Nat. Chem. 2010, 2, 286. doi: $10.1038 /$ nchem.553

(52) Ghosh, T.; Vukmirovic, M.; DiSalvo, F .; Adzic, R. J. Am. Chem. Soc. 2010, 132, 906. doi: 10.1021/ja905850c

(53) Xiao, W.; Lei, W.; Gong, M.; Xin, H. L.; Wang, D. ACS Catal. 2018, 8, 3237. doi: $10.1021 /$ acscatal.7b04420

(54) Furukawa, S.; Komatsu, T. ACS Catal. 2016, 7, 735. doi: 10.1021/acscatal.6b02603

(55) Yoo, T. Y.; Yoo, J. M.; Sinha, A. K.; Bootharaju, M. S.; Jung, E.; Lee, 
H. S.; Lee, B. H.; Kim, J.; Antink, W. H.; Kim, Y. M.; et al. J. Am. Chem. Soc. 2020, 142, 14190. doi: 10.1021/jacs.0c05140

(56) Lee, J.; Yoo, J. M.; Ye, Y.; Mun, Y.; Lee, S.; Kim, O. H.; Rhee, H. W.; Lee, H. I.; Sung, Y. E.; Lee, J. Adv. Energy Mater. 2015, 5, 1402093. doi: 10.1002/aenm.201402093

(57) Li, J.; Xi, Z.; Pan, Y. T.; Spendelow, J. S.; Duchesne, P. N.; Su, D.; Li, Q.; Yu, C.; Yin, Z.; Shen, B.; Kim, Y. S.; Zhang, P.; Sun, S. J. Am. Chem. Soc. 2018, 140, 2926. doi: 10.1021/jacs.7b12829

(58) Li, J.; Sharma, S.; Liu, X.; Pan, Y. T.; Spendelow, J. S.; Chi, M.; Jia, Y.; Zhang, P.; Cullen, D. A.; Xi, Z.; et al. Joule 2019, 3, 124. doi: 10.1016/j.joule.2018.09.016

(59) Wang, H.; Shang, P.; Zhang, J.; Guo, M.; Mu, Y.; Li, Q.; Wang, H. Chem. Mater. 2013, 25, 2450. doi: 10.1021/cm4004678

(60) Lei, W.; Xu, J.; Yu, Y.; Yang, W.; Hou, Y.; Chen, D. Nano Lett. 2018, 18, 7839. doi: 10.1021/acs.nanolett.8b03603

(61) Wang, C.; Chen, D. P.; Sang, X.; Unocic, R. R.; Skrabalak, S. E. ACS Nano 2016, 10, 6345. doi: 10.1021/acsnano.6b02669

(62) Pacchioni, G.; Freund, H. J. Chem. Soc. Rev. 2018, 47, 8474. doi: $10.1039 / \mathrm{c} 8 \operatorname{cs} 00152 \mathrm{a}$

(63) van Deelen, T. W.; Hernández Mejía, C.; de Jong, K. P. Nat. Catal. 2019, 2, 955. doi: 10.1038/s41929-019-0364-x

(64) Shim, J.; Lee, J.; Ye, Y.; Hwang, J.; Kim, S. K.; Lim, T. H. ACS Nano 2012, 6, 6870. doi: 10.1021/nn301692y

(65) Kang, E.; Jung, H.; Park, J. G.; Kwon, S.; Shim, J.; Sai, H. ACS Nano 2011, 5, 1018. doi: 10.1021/nn102451y

(66) Liu, Z.; Fu, G.; Li, J.; Liu, Z.; Xu, L.; Sun, D.; Tang, Y. Nano Res. 2018, 11, 4686. doi: 10.1007/s12274-018-2051-7

(67) Liu, H.; Dou, M.; Wang, F.; Liu, J.; Ji, J.; Li, Z. RSC Adv. 2015, 5, 66471. doi: 10.1039/c5ra12291k

(68) Kumar, V. B.; Sanetuntikul, J.; Ganesan, P.; Porat, Z. E.; Shanmugam, S.; Gedanken, A. Electrochim. Acta 2016, 190, 659. doi: $10.1016 /$ j.electacta.2015.12.193

(69) Zhu, W.; Yuan, H.; Liao, F.; Shen, Y.; Shi, H.; Shi, Y.; Xu, L.; Ma, M.; Shao, M. Chem. Eng. J. 2020, 389, 124240. doi: 10.1016/j.cej.2020.124240

(70) Wang, X. X.; Hwang, S.; Pan, Y. T.; Chen, K.; He, Y.; Karakalos, S.; Zhang, H.; Spendelow, J. S.; Su, D.; Wu, G. Nano Lett. 2018, 18 , 4163. doi: 10.1021/acs.nanolett.8b00978

(71) Chen, D.; Li, Z.; Zhou, Y.; Ma, X.; Lin, H.; Ying, W.; Peng, X. Chem. Comm. 2020, 56, 4898. doi: 10.1039/d0cc00895h

(72) Qi, Z.; Pei, Y.; Goh, T. W.; Wang, Z.; Li, X.; Lowe, M.; MaligalGanesh, R. V.; Huang, W. Nano Res. 2018, 11, 3469. doi: 10.1007/s12274-018-2016-x

(73) Hu, M.; Zhao, S.; Liu, S.; Chen, C.; Chen, W.; Zhu, W.; Liang, C.; Cheong, W. C.; Wang, Y.; Yu, Y.; et al. Adv. Mater. 2018, 30, 1801878. doi: 10.1002/adma.201801878
(74) Kwon, T.; Lim, S.; Jun, M.; Kang, M.; Joo, J.; Oh, A.; Baik, H.; Hong, C. S.; Lee, K. Nanoscale 2020, 12, 1118. doi: $10.1039 / \mathrm{c} 9 \mathrm{nr} 09318 \mathrm{~d}$

(75) Yan, Y.; Du, J. S.; Gilroy, K. D.; Yang, D.; Xia, Y.; Zhang, H. Adv. Mater. 2017, 29, 1605997. doi: 10.1002/adma.201605997

(76) Bernal, S.; Calvino, J. J.; Gatica, J. M.; Larese, C.; López-Cartes, C.; Pérez-Omil, J. A. J. Catal. 1997, 169, 510. doi: $10.1006 /$ jcat.1997.1707

(77) Maligal-Ganesh, R. V.; Xiao, C.; Goh, T. W.; Wang, L. L.; Gustafson, J.; Pei, Y.; Qi, Z.; Johnson, D. D.; Zhang, S.; Tao, F.; Huang, W. ACS Catal. 2016, 6, 1754. doi: 10.1021/acscatal.5b02281

(78) Hu, Y.; Shen, T.; Zhao, X.; Zhang, J.; Lu, Y.; Shen, J.; Lu, S.; Tu, Z.; Xin, H. L.; Wang, D. Appl. Catal. B 2020, 279, 119370. doi: 10.1016/j.apcatb.2020.119370

(79) Takahashi, Y.; Kadono, T.; Yamamoto, S.; Singh, V. R.; Verma, V. K.; Ishigami, K.; Shibata, G.; Harano, T.; Takeda, Y.; Okane, T.; et al. Phys. Rev. B 2014, 90, 024423. doi: 10.1103/PhysRevB.90.024423

(80) Qi, Z.; Xiao, C.; Liu, C.; Goh, T. W.; Zhou, L.; Maligal-Ganesh, R.; Pei, Y.; Li, X.; Curtiss, L. A.; Huang, W. J. Am. Chem. Soc. 2017, 139, 4762. doi: 10.1021/jacs.6b12780

(81) Xiao, W.; Liutheviciene Cordeiro, M. A.; Gong, M.; Han, L.; Wang, J.; Bian, C.; Zhu, J.; Xin, H. L.; Wang, D. J. Mater. Chem. A 2017, 5, 9867. doi: $10.1039 / \mathrm{c} 7 \mathrm{ta} 02479 \mathrm{~g}$

(82) Kim, J.; Rong, C.; Liu, J. P.; Sun, S. Adv. Mater. 2009, 21, 906. doi: 10.1002/adma.200801620

(83) Chen, H.; Wang, D.; Yu, Y.; Newton, K. A.; Muller, D. A.; Abruna, H.; DiSalvo, F. J. J. Am. Chem. Soc. 2012, 134, 18453. doi: $10.1021 /$ ja308674b

(84) Chen, H.; Yu, Y.; Xin, H. L.; Newton, K. A.; Holtz, M. E.; Wang, D.; Muller, D. A.; Abruña, H. D.; DiSalvo, F. J. Chem. Mater. 2013, 25, 1436. doi: $10.1021 / \mathrm{cm} 303489 \mathrm{z}$

(85) Cui, Z.; Chen, H.; Zhao, M.; DiSalvo, F. J. Nano Lett. 2016, 16, 2560. doi: 10.1021/acs.nanolett.6b00121

(86) Nguyen, M. T.; Wakabayashi, R. H.; Yang, M.; Abruña, H. D.; DiSalvo, F. J. J. Power Sources 2015, 280, 459. doi: 10.1016/j.jpowsour.2015.01.076

(87) Li, D.; Poudyal, N.; Nandwana, V.; Jin, Z.; Elkins, K.; Liu, J. P. J. Appl. Phys. 2006, 99, 08E911. doi: 10.1063/1.2166597

(88) Kim, J.; Rong, C.; Lee, Y.; Liu, J. P.; Sun, S. Chem. Mater. 2015, 20 , 7242. doi: $10.1021 / \mathrm{cm} 8024878$

(89) Yu, Y.; Sun, K.; Tian, Y.; Li, X. Z.; Kramer, M. J.; Sellmyer, D. J.; Shield, J. E.; Sun, S. Nano Lett. 2013, 13, 4975. doi: $10.1021 / \mathrm{nl} 403043 \mathrm{~d}$

(90) Wang, T.; Liang, J.; Zhao, Z.; Li, S.; Lu, G.; Xia, Z.; Wang, C.; Luo, J.; Han, J.; Ma, C.; Huang, Y.; Li, Q. Adv. Energy Mater. 2019, 9 , 1803771. doi: 10.1002/aenm.201803771 
(91) Zhang, S.; Guo, S.; Zhu, H.; Su, D.; Sun, S. J. Am. Chem. Soc. 2012, 134, 5060. doi: 10.1021/ja300708j

(92) Kuttiyiel, K. A.; Sasaki, K.; Su, D.; Wu, L.; Zhu, Y.; Adzic, R. R. Nat. Commun. 2014, 5, 5185. doi: 10.1038/ncomms6185

(93) Yan, Q.; Kim, T.; Purkayastha, A.; Ganesan, P. G.; Shima, M.; Ramanath, G. Phys. Inorg. Chem. 2005, 17, 2233. doi: $10.1002 / \operatorname{chin} .200546012$

(94) Takahashi, Y. K.; Ohnuma, M.; Hono, K. J. Magn. Magn. Mater. 2002, 246, 259. doi: 10.1016/S0304-8853(02)00065-3

(95) Kang, S.; Harrell, J. W.; Nikles, D. E. Nano Lett. 2002, 2, 1033. doi: $10.1021 / \mathrm{n} 1025614 \mathrm{~b}$

(96) Rong, H.; Mao, J.; Xin, P.; He, D.; Chen, Y.; Wang, D.; Niu, Z.; Wu, Y.; Li, Y. Adv. Mater. 2016, 28, 2540. doi: 10.1002/adma.201504831

(97) Cheong, S.; Watt, J.; Ingham, B.; Toney, M. F.; Tilley, R. D. J. Am. Chem. Soc. 2009, 131, 14590. doi: 10.1021/ja9065688

(98) Chen, W.; Yu, R.; Li, L.; Wang, A.; Peng, Q.; Li, Y. Angew. Chem. Int. Ed. 2010, 49, 2917. doi: 10.1002/anie.200906835

(99) Bu, L.; Zhang, N.; Guo, S.; Zhang, X.; Li, J.; Yao, J. Science 2016, 354, 1410. doi: 10.1126/science.aah6133

(100) Qin, Y.; Luo, M.; Sun, Y.; Li, C.; Huang, B.; Yang, Y.; Li, Y.; Wang, L.; Guo, S. ACS Catal. 2018, 8, 5581. doi: 10.1021/acscatal.7b04406

(101) Stamenkovic, V. R.; Fowler, B.; Mun, B. S.; Wang, G.; Ross, P. N.; Lucas, C. A. Science 2007, 315, 493. doi: 10.1126/science.1135941

(102) Zhang, X.; Tian, S.; Yu, W.; Lu, B.; Shen, T.; Xu, L.; Sun, D.; Zhang, S.; Tang, Y. CrystEngComm 2018, 20, 4277. doi: $10.1039 / \mathrm{c} 8 \mathrm{ce} 00601 \mathrm{f}$

(103) Liu, S.; Han, L.; Zhu, J.; Xiao, W.; Wang, J.; Liu, H.; Xin, H.; Wang, D. J. Mater. Chem. A 2015, 3, 20966. doi: $10.1039 / \mathrm{c} 5 \mathrm{ta} 05202 \mathrm{e}$

(104) Bu, L.; Shao, Q.; E, B.; Guo, J.; Yao, J.; Huang, X. J. Am. Chem. Soc. 2017, 139, 9576. doi: 10.1021/jacs.7b03510

(105) Wang, C.; Sang, X.; Gamler, J. T. L.; Chen, D. P.; Unocic, R. R.; Skrabalak, S. E. Nano Lett. 2017, 17, 5526. doi: 10.1021/acs.nanolett.7b02239

(106) Wang, G.; Huang, B.; Xiao, L.; Ren, Z.; Chen, H.; Wang, D.; Abruna, H. D.; Lu, J.; Zhuang, L. J. Am. Chem. Soc. 2014, 136, 9643. doi: $10.1021 / \mathrm{ja} 503315 \mathrm{~s}$

(107) Guo, S.; Zhang, X.; Zhu, W.; He, K.; Su, D.; Mendoza-Garcia, A.; Ho, S. F.; Lu, G.; Sun, S. J. Am. Chem. Soc. 2014, 136, 15026. doi: $10.1021 / \mathrm{ja} 508256 \mathrm{~g}$

(108) Jiang G.; Zhu H.; Zhang X.; Shen B.; Wu L.; Zhang S.; Lu G.; Wu Z.; Sun S. ACS Nano 2015, 9, 11014. doi: 10.1021/acsnano.5b04361

(109) Zhao, X.; Xi, C.; Zhang, R.; Song, L.; Wang, C.; Spendelow, J. S.; Frenkel, A. I.; Yang, J.; Xin, H. L.; Sasaki, K. ACS Catal. 2020, 10637. doi: 10.1021 /acscatal.0c03036
(110) Wang, D.; Yu, Y.; Zhu, J.; Liu, S.; Muller, D. A.; Abruna, H. D. Nano Lett. 2015, 15, 1343. doi: 10.1021/n1504597j

(111) Li, L.; Larsen, A. H.; Romero, N. A.; Morozov, V. A.; Glinsvad, C.; Abild-Pedersen, F.; Greeley, J.; Jacobsen, K. W.; Norskov, J. K. J. Phys. Chem. Lett. 2013, 4, 222. doi: 10.1021/jz3018286

(112) Yang, Y.; Xiao, W.; Feng, X.; Xiong, Y.; Gong, M.; Shen, T.; Lu, Y.; Abruna, H. D.; Wang, D. ACS Nano 2019, 13, 5968. doi: 10.1021/acsnano.9b01961

(113) Kuttiyiel, K. A.; Kattel, S.; Cheng, S.; Lee, J. H.; Wu, L.; Zhu, Y.; Park, G. G.; Liu, P.; Sasaki, K.; Chen, J. G.; Adzic, R. R. ACS Appl. Energy Mater. 2018, 1, 3771. doi: 10.1021/acsaem.8b00555

(114) He, Y.; Wu, Y. L.; Zhu, X. X.; Wang, J. N. ACS Appl. Mater Interfaces 2019, 11, 11527. doi: 10.1021/acsami.9b01810

(115) Liang, J.; Li, N.; Zhao, Z.; Ma, L.; Wang, X.; Li, S.; Liu, X.; Wang, T.; Du, Y.; Lu, G.; Han, J.; Huang, Y.; Su, D.; Li, Q. Angew. Chem. Int. Ed. 2019, 58, 15471. doi: 10.1002/anie.201908824

(116) Dhavale, V. M.; Kurungot, S. ACS Catal. 2015, 5, 1445. doi: $10.1021 / \operatorname{cs} 501571 \mathrm{e}$

(117) Gong, M.; Xiao, D.; Deng, Z.; Zhang, R.; Xia, W.; Zhao, T.; Liu, X.; Shen, T.; Hu, Y.; Lu, Y.; et al. Appl. Catal. B 2021, 282, 119617. doi: 10.1016/j.apcatb.2020.119617

(118) Ao, X, Zhang, W , Zhao, B.; Ding, Y.; Liu, M. Energy Environ. Sci. 2020, 13, 3032.doi: 10.1039/D0EE00832J

(119) Zhao, X.; Yin, M.; Ma, L.; Liang, L.; Liu, C.; Liao, J.; Lu, T.; Xing, W. Energy Environ. Sci. 2011, 4, 2736. doi: 10.1039/c1ee01307f

(120) Rossmeisl, J.; Ferrin, P.; Tritsaris, G. A.; Nilekar, A. U.; Koh, S.; Bae, S. E.; Brankovic, S. R.; Strasser, P.; Mavrikakis, M. Energy Environ. Sci. 2012, 5, 8335. doi: 10.1039/c2ee21455e

(121) Scofield, M. E.; Zhou, Y.; Yue, S.; Wang, L.; Su, D.; Tong, X.; Vukmirovic, M. B.; Adzic, R. R.; Wong, S. S. ACS Catal. 2016, 6, 3895. doi: 10.1021/acscatal.6b00350

(122) Wang, Y.; Wang, G.; Li, G.; Huang, B.; Pan, J.; Liu, Q.; Han, J.; Xiao, L.; Lu, J.; Zhuang, L. Energy Environ. Sci. 2015, 8, 177. doi: $10.1039 / \mathrm{c} 4$ ee $02564 d$

(123) Innocente, A. F.; Ângelo, A. C. D. J. Power Sources 2006, 162, 151. doi: 10.1016/j.jpowsour.2006.06.057

(124) Santos, E.; Pinto, L. M. C.; Soldano, G.; Innocente, A. F.; Ângelo, A. C. D.; Schmickler, W. Catal. Today 2013, 202, 191. doi: 10.1016/j.cattod.2012.07.044

(125) Bortoloti, F.; Garcia, A. C.; Angelo, A. C. D. Int. J. Hydrogen Energy 2015, 40, 10816. doi: 10.1016/j.ijhydene.2015.06.145

(126) Zhao, T.; Hu, Y.; Gong, M.; Lin, R.; Deng, S.; Lu, Y.; Liu, X.; Chen, Y.; Shen, T.; Hu, Y.; et al. Nano Energy 2020, 74, 104877. doi: 10.1016/j.nanoen.2020.104877

(127) Kang, Y.; Qi, L.; Li, M.; Diaz, R. E.; Su, D.; Adzic, R. R. ACS Nano 2012, 6, 2818. doi: 10.1016/j.ijhydene.2015.06.145 
(128) Vidal-Iglesias, F. J.; Lopez-Cudero, A.; Solla-Gullon, J.; Feliu, J. M. Angew. Chem. Int. Ed. 2013, 52, 964. doi: 10.1002/anie.201207517

(129) Alden, L. R.; Han, D. K.; Matsumoto, F.; Héctor D. Abruña.; Disalvo, F. J. Chem. Mater. 2006, 18, 5591. doi: 10.1021/cm060927j

(130) Luo, S.; Chen, W.; Cheng, Y.; Song, X.; Wu, Q.; Li, L.; Wu, X.; Wu, T.; Li, M.; Yang, Q.; Deng, K.; Quan, Z. Adv. Mater. 2019, 31, e1903683. doi: 10.1002/adma.201903683

(131) Shen, T.; Zhang, J.; Chen, K.; Deng, S.; Wang, D. Energy Fuels 2020, 34, 9137. doi: 10.1021/acs.energyfuels.0c01820

(132) Roychowdhury, C.; Matsumoto, F.; Zeldovich, V. B.; Warren, S. C.; Mutolo, P. F.; Ballesteros, M. J. Chem. Mater. 2006, 18, 3365. doi: $10.1021 / \mathrm{cm} 060480 \mathrm{e}$

(133) Liu, Y.; Lowe, M. A.; Finkelstein, K. D.; Dale, D. S.; DiSalvo, F. J.; Abruna, H. D. Chem 2010, 16, 13689.

doi: $10.1002 /$ chem. 201001211

(134) Wang, C. Y.; Yu, Z. Y.; Li, G.; Song, Q. T.; Li, G.; Luo, C. X.; Yin, S. H.; Lu, B. A.; Xiao, C.; Xu, B. B.; et al. ChemElectroChem 2020, 7, 239. doi: $10.1002 /$ celc. 201901818

(135) Zhu, J.; Zheng, X.; Wang, J.; Wu, Z.; Han, L.; Lin, R.; Xin, H. L.; Wang, D. J. Mater. Chem. A 2015, 3, 22129. doi: $10.1039 / \mathrm{c} 5 \mathrm{ta} 05699 \mathrm{c}$

(136) Chen, L.; Zhu, J.; Xuan, C.; Xiao, W.; Xia, K.; Xia, W.; Lai, C.; Xin, H. L.; Wang, D. J. Mater. Chem. A 2018, 6, 5848. doi: $10.1039 / \mathrm{c} 7 \mathrm{ta} 11051 \mathrm{k}$

(137) Wang, J. Y.; Zhang, H. X.; Jiang, K.; Cai, W. B. J. Am. Chem. Soc. 2011, 133, 14876. doi: 10.1021/ja205747j

(138) Sun, D.; Si, L.; Fu, G.; Liu, C.; Sun, D.; Chen, Y.; Tang, Y.; Lu, T. J. Power Sources 2015, 280, 141. doi: 10.1016/j.jpowsour.2015.01.100

(139) Shen, T.; Lu, Y.; Gong, M.; Zhao, T.; Hu, Y.; Wang, D. ACS Sustain. Chem. Eng. 2020, 8, 12239. doi: 10.1021/acssuschemeng.0c03881

(140) Jana, R.; Subbarao, U.; Peter, S. C. J. Power Sources 2016, 301, 160. doi: 10.1016/j.jpowsour.2015.09.114

(141) Kang, Y.; Qi, L.; Li, M.; Diaz, R. E.; Su, D.; Adzic, R. R.Stach, E.; Li, J.; Murray, C. B. ACS Nano 2012, 6, 2818. doi: 10.1016/j.ijhydene.2015.06.145

(142) Mun, Y.; Shim, J.; Kim, K.; Han, J. W.; Kim, S. K.; Ye, Y.; Hwang, J.; Lee, S.; Jang, J.; Kim, Y. T.; Lee, J. RSC Adv. 2016, 6, 88255. doi: $10.1039 / \mathrm{c} 6 \mathrm{ra} 14861 \mathrm{a}$

(143) An, L.; Yan, H.; Li, B.; Ma, J.; Wei, H.; Xia, D. Nano Energy 2015, 15, 24. doi: 10.1016/j.nanoen.2015.03.031

(144) Zhu, J.; Yang, Y.; Chen, L.; Xiao, W.; Liu, H.; Abruña, H. D.; Wang, D. Chem. Mater. 2018, 30, 5987. doi: 10.1021/acs.chemmater.8b02172
(145) Zeng, R.; Yang, Y.; Shen, T.; Wang, H.; Xiong, Y.; Zhu, J.; Wang, D.; Abruña, H. D. ACS Catal. 2019, 10, 770. doi: $10.1021 /$ acscatal.9b04344

(146) Chen, Q.; Zhang, J.; Jia, Y.; Jiang, Z.; Xie, Z.; Zheng, L. Nanoscale 2014, 6, 7019. doi: 10.1039/c4nr00313f

(147) Feng, Q.; Zhao, S.; He, D.; Tian, S.; Gu, L.; Wen, X.; Chen, C.; Peng, Q.; Wang, D.; Li, Y. J. Am. Chem. Soc. 2018, 140, 2773. doi: $10.1021 /$ jacs.7b13612

(148) Yuan, X.; Jiang, X.; Cao, M.; Chen, L.; Nie, K.; Zhang, Y.; Xu, Y.; Sun, X.; Li, Y.; Zhang, Q. Nano Res. 2018, 12, 429. doi: $10.1007 / \mathrm{s} 12274-018-2234-2$

(149) Kang, Y.; Murray, C. B. J. Am. Chem. Soc. 2010, 132, 7568. doi: $10.1021 / \mathrm{ja} 100705 \mathrm{j}$

(150) Farias, M. J. S.; Cheuquepan, W.; Tanaka, A. A.; Feliu, J. M. J. Phys. Chem. Lett. 2018, 9, 1206. doi: 10.1021/acs.jpclett.8b00030

(151) Kodiyath, R.; Ramesh, G. V.; Koudelkova, E.; Tanabe, T.; Ito, M.; Manikandan, M.; Ueda, S.; Fujita, T.; Umezawa, N.; Noguchi, H.; et al. Energy Environ. Sci. 2015, 8, 1685. doi: 10.1039/c4ee03746d

(152) Sarkar, S.; Jana, R.; Suchitra; Waghmare, U. V.; Kuppan, B.; Sampath, S.; Peter, S. C. Chem. Mater. 2015, 27, 7459. doi: 10.1021/acs.chemmater.5b03546

(153) Wang, C.; Wu, Y.; Wang, X.; Zou, L.; Zou, Z.; Yang, H. Electrochim. Acta 2016, 220, 628 . doi: 10.1016/j.electacta.2016.10.094

(154) Zhang, W.; Wang, R.; Wang, H.; Lei, Z. Fuel Cells 2010, 10, 734. doi: 10.1002/fuce.200900184

(155) Singh, R. N.; Singh, A.; Anindita, Int. J. Hydrogen Energy 2009, 34, 2052. doi: 10.1016/j.ijhydene.2008.12.047

(156) Pattabiraman, R. Appl. Catal. A 1997, 153, 9. doi: 10.1016/j.ijhydene.2008.12.047

(157) Jiang, K.; Wang, P.; Guo, S.; Zhang, X.; Shen, X.; Lu, G.; Su, D.; Huang, X. Angew. Chem. 2016, 128, 9176. doi: 10.1002/ange.201603022

(158) Serov, A.; Martinez, U.; Atanassov, P. Electrochem. Commun. 2013, 34, 185. doi: 10.1016/j.elecom.2013.06.003

(159) Shi, Q.; Zhu, C.; Bi, C.; Xia, H.; Engelhard, M. H.; Du, D.; Lin, Y. J. Mater. Chem. A 2017, 5, 23952. doi: 10.1039/c7ta08407b

(160) Zhu, Y.; Bu, L.; Shao, Q.; Huang, X. ACS Catal. 2020, 10, 3455. doi: $10.1021 /$ acscatal.9b04313

(161) Yun, Q.; Lu, Q.; Li, C.; Chen, B.; Zhang, Q.; He, Q.; Hu, Z.; Zhang, Z.; Ge, Y.; Yang, N.; et al. ACS Nano 2019, 13, 14329. doi: 10.1021/acsnano.9b07775 